University of Rhode Island

DigitalCommons@URI

Open Access Master's Theses

1997

\title{
The Effects of Practice on Auditory Vigilance Task Performance
}

Kristen A. McKiernan

University of Rhode Island

Follow this and additional works at: https://digitalcommons.uri.edu/theses

\section{Recommended Citation}

McKiernan, Kristen A., "The Effects of Practice on Auditory Vigilance Task Performance" (1997). Open Access Master's Theses. Paper 1564.

https://digitalcommons.uri.edu/theses/1564

This Thesis is brought to you for free and open access by DigitalCommons@URI. It has been accepted for inclusion in Open Access Master's Theses by an authorized administrator of DigitalCommons@URI. For more information, please contact digitalcommons-group@uri.edu. 
323

\section{5}

$M 3$

THE EFFECTS OF PRACTICE ON AUDITORY VIGILANCE TASK

PERFORMANCE

BY

KRISTEN A, MCKIERNAN

A THESIS SUBMITTED IN PARTIAL FULFILLMENT OF THE REQUIREMENTS FOR THE DEGREE OF

MASTER OF ARTS

IN

PSYCHOLOGY

UNIVERSITY OF RHODE ISLAND

1997

38314096 


\begin{abstract}
To determine the effects of practice on auditory vigilance task performance, twenty-eight individuals completed five sessions of testing of auditory Continuous Performance Tests (CPTs). Two types of computerized CPTs were employed, a cognitive task using letters of the alphabet as stimuli, and a sensory task using tones as stimuli. Each participant heard either the letter or the tone task daily for five days and additionally heard the other task on the first and last day. Participants responded to targets, which were two immediately successive stimuli that were exactly the same, by pressing a button connected to the computer. Both tasks lasted for 15 minutes and were equivalent in terms of target number and placement. Data were broken down by task, day and three minute blocks within each day. Dependent measures collected by the computer were accuracy, reaction time, and number of false alarms. A second focus of this study was to further investigate the differences noted in the literature regarding differences in vigilance decrement for sensory and cognitive tasks. A third goal was to evaluate the reliability of these two CPT tasks.
\end{abstract}

The results of repeated measures ANOVAs indicated that performance as measured by reaction time, accuracy, and number of false alarms did not change significantly with practice. Additionally, vigilance and latency decrements did not significantly vary between tasks or across days. The test-retest reliability of the CPT was determined to be moderate based on correlations over days for each of the performance measures. Interpretations of these results are discussed. 


\section{TABLE OF CONTENTS}

List of Tables ......................................................................

List of Figures ...................................................................

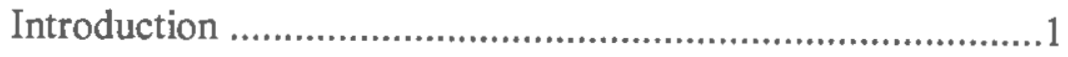

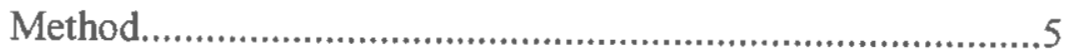

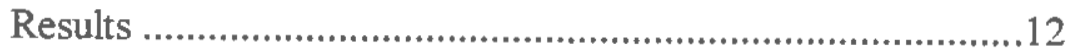

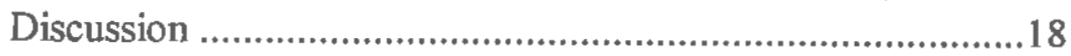

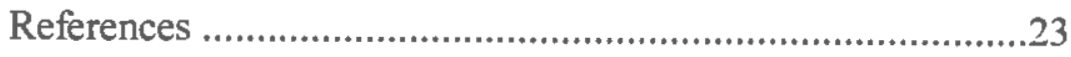

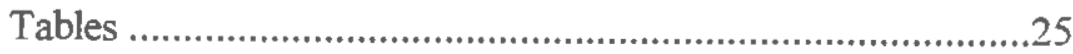

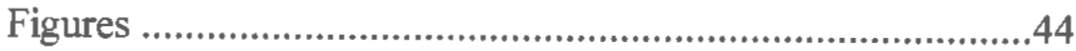

Appendix A: Consent Form................................................52

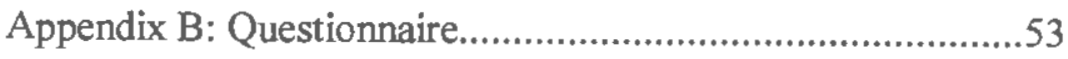

Appendix C: Daily Questionnaire.........................................58

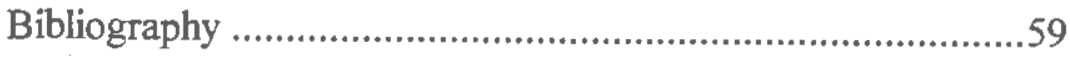




\section{LIST OF TABLES}

No. Title

Page

1 Practiced Task Reaction Time and Accuracy Means and Standard

Deviations for Day and Block by Task

2 ANOVA Summary Table for $2 \times 5 \times 5$ TASKx(DAYxBLOCK) Analysis for 26

Reaction Time

3 ANOVA Summary Table for $2 \times 5 \times 5$ TASKx(DAYxBLOCK) Analysis for 27

Accuracy

4 Practiced Task Latency Decrement and Vigilance Decrement Summary $\quad 28$

Data for Day and Block by Task

5 ANOVA Summary Table for 2x5 TASKx(DAY) Analysis for Vigilance

Decrement

6

ANOVA Summary Table for 2x5 TASKx(DAY) Analysis for Latency

Decrement

7 ANOVA Summary Table for $2 \times 5 \times 2$ TASKx(DAYxBLOCK) Analysis for 31 Latency Decrement

8 ANOVA Summary Table for $2 \times 5 \times 2$ TASKx(DAYxBLOCK) Analysis for 32 Vigilance Decrement

9 ANOVA Summary Table for $2 \times 5 \times 5$ TASKx(DAYxBLOCK) Analysis for 33 False Alarms

10 Practiced Task Average Number of False Alarms Made by Day and Block 34 by Task 
No. Title

Page

11 Unpracticed Task Means and Standard Deviations for Reaction Time, 35 Accuracy, and False Alarms by Task

12 Unpracticed Task ANOVA Summary Table for $2 \times 2$ TASKx(DAY) Analysis for Reaction Time

13 Unpracticed Task ANOVA Summary Table for $2 \times 2$ TASKx(DAY) 37 Analysis for Accuracy

14 Unpracticed Task ANOVA Summary Table for $2 \times 2$ TASKx(DAY) 38 Analysis for False Alarms

15 Unpracticed Task Mean Reaction Time, Accuracy, and Latency and 39 Vigilance Decrements by Task

16 Unpracticed Task ANOVA Summary Table for $2 \times 5$ TASKx(DAY) 40 Analysis for Latency Decrement

17 Unpracticed Task ANOVA Summary Table for $2 \times 5$ TASKx(DAY) Analysis for Vigilance Decrement

18 Practiced Tone Task Correlations for All Performance Measures by Day 42 19 Practiced Letter Task Correlations for All Performance Measures by Day 43 


\section{LIST OF FIGURES}

$\begin{array}{lll}\text { No. Title } & \text { Page }\end{array}$

1 Practiced Task Mean Reaction Time by Day and Block 44

2 Practiced Task Mean Accuracy by Day and Block 45

3 Combined Tasks Mean Reaction Time Across Days 46

$4 \quad$ Practiced Task Mean Vigilance Decrement by Day and Block 47

$5 \quad$ Practiced Task Mean Latency Decrement by Day and Block 48

6 Practiced Task Mean Number of False Alarms Made by Day and Block 49

$7 \quad$ Unpracticed Task Number of False Alarms Made by Task 50

$8 \quad$ Unpracticed Task Vigilance Decrements by Task 51 


\section{INTRODUCTION}

Sustained attention or vigilance has been studied extensively over the past four decades. Vigilance has been described as the ability of observers to maintain their focus of awareness and remain alert to stimuli for prolonged periods of time (Davies and Parasuraman, 1982; Koelega, Brinkman, Hendriks \& Verbaten, 1989; See, Howe, Warm \& Dember, 1995; Warm, 1984; Williams, 1986). Research has established that over time a decline in performance efficiency occurs (Davies \& Parasuraman, 1982; Halperin, Sharma, Greenblatt \& Schwartz, 1991; Koelega, 1996; Koelega et al., 1989; See et al., 1995; Swets \& Kristofferson, 1970; Warm, 1984; Williams, 1986). This decline is known as the vigilance decrement. According to See, Howe, Warm \& Dember (1995), the vigilance decrement is measured as a decline in the percentage of correctly detected signals over time.

A variety of factors impact an individual's ability to sustain attention, including time of day, memory load, background event rate, target discrimination type (successive versus simultaneous discrimination, sensory versus cognitive discrimination), sensory modality, number of sources to be monitored, heat stress, individual motivation, subject's locus of control, signal expectancy, spatial uncertainty, and signal complexity (Fisk and Scerbo, 1987). Most of these factors have been studied extensively in the context of vigilance (See et al., 1995); some were initially addressed by Parasuraman and Davies (1977) in their taxonomy of vigilance performance.

Parasuraman and Davies (1977) proposed a taxonomy of vigilance performance that categorized vigilance tasks across two dimensions: type of discrimination (successive or simultaneous) and event rate (high or low). They defined successive tasks as those that 
required the participant to discriminate between stimuli by keeping a standard in working memory and comparing successively presented stimuli to that standard. Simultaneous tasks were defined as comparative judgment tasks in which a discrimination could be made based only on the information inherent in each individual stimulus. There is no requirement for working memory to be involved in this type of task. Event rate is determined by the rate of presentation of the background stimulus events in which the critical signals (targets) to be detected are embedded (See, et al., 1995). The taxonomy labels the event rate as "high" when the rate is 24 events/minute or higher, and "low" when the event rate falls below this mark.

More recently, revisions to this taxonomy have explored the possibility of adding other dimensions such as type of stimuli used (cognitive versus sensory) and motivation (Koelega et al., 1989; See et al., 1995). See et al.(1995) use a rather loose definition of "cognitive" and "sensory" stimuli. A stimulus is considered cognitive if it is alpha-numeric and as such, has meaning attached to it even if at a very basic level; it is sensory if it is not alpha-numeric (e.g., tone, volume, or other physical change to the stimulus) and therefore does not have "meaning". Koelega et al. (1989) hypothesized that "one of the critical dimensions affecting total task demand might be the basic distinction between sensory and cognitive vigilance tasks".

Fisk and Scerbo (1987) point out that there are two parameters that are usually not addressed in vigilance research. One of these parameters is the effect of practice on vigilance performance, and the other is the effect of the consistency between the stimulus and the associated response. Schneider and Fisk (1982) state that "because human performance has been shown to be a multiplicative function of the degree of the 
consistency between a given stimulus and its associated response and the amount of practice, it seems reasonable that these factors should also affect vigilance performance".

The literature contains few studies in which the main focus was to examine the practice effects associated with repeated testing on a vigilance task (Binford and Loeb, 1966; Fisk and Scerbo, 1987; Leek \& Watson, 1988; Neisser \& Hirst, 1974; Nickerson \& Freeman, 1974; Williams, 1986). In these studies in which practice effect was discussed at all, the focus was on the effect that practice had on the subject's ability to reduce the time required to discriminate between stimuli (Leek \& Watson, 1988; Neisser \& Hirst, 1974; Nickerson \& Freeman, 1974) and therefore perform at increasingly faster stimuli presentation rates. None of the studies cited here were similar to this study in terms of the classification of the tasks and the main focus on improving task performance over time.

Several vigilance studies (Binford and Loeb, 1966; Williams, 1986) have concluded that training on a vigilance task does not affect performance. They found decrements in vigilance performance even for highly trained subjects. In their metaanalysis of 42 vigilance studies, See, Howe, Warm \& Dember (1995) found that neither training time nor the length of the vigilance task were among the factors that significantly contributed to explaining decrements in vigilance. Along with Koelega et al. (1989), they specifically claim that although level of vigilance performance will decline for all tasks, sensitivity decrements occur only when the task contains sensory stimuli; it is not observed with cognitive stimuli. Williams (1986) conducted a study in which he found that sensitivity decrements occurred in tasks using successive discrimination and a low event rate (20 events/min); his study employed visual sensory stimuli. Sensitivity decrement can be thought of as the decline in performance that occurs due to habituation or decline in 
perceptual sensitivity to stimuli (See et al., 1995). See et al. also note that the sensitivity decrement is dependent on type of discrimination required, event rate, and type of stimuli presented.

One objective of the present study was to investigate the effects of manipulating stimulus type on measures of performance for sustained attention. To do this, two tasks, one using cognitive stimuli (letters) and one using sensory stimuli (tones) were developed. According to Koelega et al. (1989), this qualifies our former task as cognitive and the latter as sensory. These tone and letter vigilance tasks are categorized by Parasuraman and Davies' taxonomy (1977) as successive, high event tasks. In both the tone task and the letter task, a target consists of two identical stimuli (either same tone or same letter) in a row. This requires the subject to compare each stimulus to the previous one and make a decision. These two Continuous Performance Tasks (CPTs) were used to examine the effect of practice on sustained attention by training subjects on one task and testing them on both tasks. Each task was fifteen minutes in duration. See et al. (1995) cite the results of Teichner's (1974) vigilance experiments stating that the decrement in vigilance performance is typically complete after 20 to 35 minutes of a vigilance session, and at least half of the total loss occurs during the first 15 minutes of the session. Based on this information and on general time constraints for testing subjects, each task in this study was fifteen minutes in length. Fifteen minutes should be long enough to allow for a measurable vigilance decrement without being too time intensive for the subject.

This study was exploratory in nature; it was an attempt to further investigate the differences noted in the literature regarding differences in vigilance decrement for sensory and cognitive tasks, as well as to analyze the effects of practice on measures of sustained 
attention. The performance measures that were collected include the following variables: accuracy (percent of targets correctly "hit"), reaction time, and false alarms (number of false alarms made). The repeated measures ANOVAs for reaction time and accuracy and the repeated measures ANOVAs for vigilance decrement and latency decrement were the main tests for practice effects. The repeated measures ANOVA, with false alarms as the dependent variable was the more exploratory analysis.

The presence of a practice effect for vigilance has some important implications. It may show that vigilance decrements can be minimized or at least reduced with practice on a task. This information could be useful to people whose jobs require long periods of vigilance or for those people who have an attention deficit; with practice they may be able to maintain attention longer or experience less of a decline when their attention does waver. A third focus of this study was to evaluate the reliability of these two CPT tasks. Both types of CPT tasks are used in clinical settings and research, therefore the test-retest reliability is very relevant. This study, with its repeated administrations of the tasks is an ideal opportunity to evaluate the test-retest reliability. High correlations for each performance measure across the five days will indicate that the tasks are reliable.

\section{METHOD}

The IRB number under which this data was collected is H9596-112.

\section{Participants}

The participants for this study were recruited from the University of Rhode Island campus. They were a mixture of graduate and undergraduate students. Undergraduate students who were enrolled in introductory psychology classes received some course credit for participating. A total of 41 students were tested; 12 participants were dropped 
due to incomplete data, and one was excluded based on medical history and current prescription drug use. Of the 28 individuals who completed all five test sessions, 15 were male and 13 were female. Their average age was 21.65 years $(\mathrm{SD}=6.44)$ with a range of 18.01 years to 45.9 years. Individuals may have been excluded from this study based on acknowledging a previous head injury, loss of consciousness, diagnosed learning disability, neurological disorder, hearing problem, or history of drug/alcohol abuse. All participants signed a consent form (Appendix A) prior to testing.

\section{Equipment}

A Gateway 2000 IBM compatible personal computer was used to administer these two computerized auditory CPTs and collect and score the performance measures. The stimuli were presented over stereo headphones. Sound Blaster Pro software was used to articulate the letters and tones. During all test sessions, a white noise generator was employed at a consistent level which was loud enough to mask noise from outside the laboratory. The white noise was generated from a position that was located approximately $21 / 2$ feet directly behind the seated subject. Subjects responded to target stimuli by pressing a hand-held, continuous interrupt button that was connected to the computer.

\section{Tests \& Questionnaires}

Background data were collected by asking each subject to complete an initial questionnaire (Appendix B) that screened for head injuries, hearing impairments, alcohol/nicotine use, medications, learning disabilities, and handedness. Each participant also completed pre- and post test Visual Analog Mood Scales (VAMS) daily. Analysis of the VAMS data was not be pursued in this particular study. On subsequent days of 
testing, each participant was asked to complete a brief daily questionnaire (Appendix C) designed to monitor intake of caffeine, nicotine, and alcohol during the previous 24 hours. Additional information concerning amount of sleep, medications and occurrence of any new stressors was also collected by this questionnaire.

$\underline{\text { Tasks }}$

This study employed a fifteen minute audio letter version of the CPT as well as a tone version of the same length. For both tasks, the stimuli were presented at an onset-toonset rate of . 75 seconds. Previous research in our laboratory has shown that at faster onset-to-onset rates the accuracy rate on the tone task is substantially lower than for the letter task, indicating that at those rates the tone test is more difficult than the letter task. At slower onset-to-onset rates a ceiling effect is observed for accuracy on the letter task. Over the course of either task, the subject heard 1200 stimuli, 100 of which were target stimuli. Targets semi-randomly occurred at an average rate of one every nine seconds. There were no instances in which a target was immediately followed by another target (i.e., a $\underline{\mathrm{a}} \mathrm{b} \underline{\mathrm{b}}$ ). For each task there were five versions of the stimulus sequence; the original sequence of 1200 stimuli were divided into five blocks of 240 stimuli each (3 minutes). The other four sequences were constructed by systematically rearranging the order of the five blocks. Each participant heard a different sequence at each test session. This mitigated the possibility that any improvement in performance would be attributable to learning the sequence and anticipating the targets. Additionally, the order of presentation of the five sequences across the five days of testing was systematically varied over all participants. The original letter and tone sequences were almost identical with respect to target location. During the rearrangement of the blocks for the construction of the other 
four sequences for each task, several minor changes in target location had to be made, however number of targets per task as well as per block remained constant.

The letter task consists of a semi-random series of letters of the alphabet (" $w$ " is the only letter not included) as stimuli. Participants pressed the button once every time they heard a letter that was identical to the preceding letter; two identical stimuli in a row constituted a target.

The tone task consists of a semi-random series of eight tones (constituting one octave of the standard major diatonic musical scale) as stimuli. Participants pressed the button once every time they heard a tone that was identical to the preceding tone; two identical stimuli in a row constituted a target. For ease of distinction, target tones were at least two notes higher or lower than the note that preceded or followed the target pair.

\section{Procedure}

Participants were tested individually. Each participant was tested five times over a six day period (Sunday-Friday). As scheduling permitted, each person was tested at approximately the same time of day across all five test sessions. The decision to test each subject five times was based on several factors. First, extending the testing across too many days would allow the potential for a variety of outside influences to contaminate the subject's performance. Some of these influences include sickness, school related stressesa paper or exam, and weekend activities (alcohol and drug use). At the same time, enough test sessions were needed for the subject to exhibit an effect due to practice. Hence, the six days were chosen, and the subject was required to participate in testing on five of those days. On Day 1 both a letter and tone version of the CPT were administered, each preceded by a short practice session that aquainted the participant with the task and 
ascertained that they understood the instructions. A three minute rest period separated the presentation of the different tasks.

There were two conditions which were counterbalanced across subjects. One condition presented the letter task every day (the repeated task) and the tone task only on days 1 and 5 (the unpracticed task). The second condition presented the tone task as the repeated task and the letter task as the unpracticed task. Regardless of condition, the order of presentation of the tasks to each participant remained constant. On Day 1, the order was as follows: unpracticed task practice, unpracticed task test, 3 minute rest, repeated task practice, repeated task test. For Days 2-4 only the repeated task was presented. On Day 5 the repeated task was presented first, followed by a 3 minute rest break, then the unpracticed task.

The testing process began when the participant signed the consent form on Day 1. At this time the participant also completed the screening questionnaire and pre-test VAMS. Testing began by sitting the subject in a chair and reading the instructions to explain the task. Subjects were given the headphones over which the stimuli were presented, and allowed to adjust them for fit and comfort. The response button was placed in their preferred hand, which was determined by their responses to the handedness questionnaire section of the screening questionnaire. Each person was instructed to use the thumb of their preferred hand to depress the button. The room lights were extinguished, and the white noise machine was turned on. The appropriate sequence(s) were then presented to the individual. 
Scoring

The measures of performance collected by the computer were: percent of "hits", correct responses to targets referred to as accuracy; "misses", errors of omission; "false alarms", errors of commission; and response reaction time. A scoring program designed by Kevin Smith (University of Rhode Island) was used to score the CPT data. The scoring program allowed a maximum reaction time of up to 1300 milliseconds after target onset for a response to a target to be categorized as a hit. The program also allowed the researcher to specify certain "blocks" of stimuli to be scored. This particular feature was used to analyze daily performance as occurring in five 3 minute blocks. The scored and calculated data were imported into both Excel 5.0 and SPSS for Windows 6.0 for statistical analysis.

\section{Data Analyses}

A pre-test power analysis could not be conducted due to a lack of available data to use in the calculation of effect size; as mentioned, a study of this type has not been conducted. Exploratory data analysis was conducted to assess the integrity of the data against the statistical assumptions. The dependent variables throughout the analyses came from the performance measures mentioned above. The independent variables were TASK (tone or letter), DAY (1-5), and BLOCK (1-5). In the case of missing data, that subject was completely excluded from the data analysis.

Repeated Task. The main focus of this study was on the effect of practice on measures of attention. The presence of a practice effect for the repeated task was evaluated by two $2 \times 5 \times 5$ TASK $\times$ (DAY $\times$ BLOCK) repeated measures Analysis of Variance (ANOVAs), one with reaction time as the dependent variable and the other with 
accuracy as the dependent variable. The alpha level was set at .05 for these and all subsequent analyses. Corrections for familywise error rates were not made based on the exploratory nature of the study. Based on significant results, follow up tests using special error terms were conducted as required to determine how performance changed over time.

Two $2 \times 5$ TASK $\times(D A Y)$ repeated ANOVAs assessed the decrement in accuracy and reaction time over the 15 minute tasks. Vigilance decrement is the change in vigilance level (accuracy) over time. Latency decrement is the change in reaction time over time. The decrement was computed for each subject by subtracting Block 5 from Block 1 (performance during first 3 minutes - performance during last three minutes) for each day for each performance measure (reaction time and accuracy) for each task. A significant TASK $x$ BLOCK effect would indicate that vigilance decrement on the two tasks differed, and further analyses would investigate whether the data support the literature. A significant BLOCK effect would indicate that during a 15 minute task, a significant vigilance decrement occurred (with regards to accuracy) or that a significant latency decrement occurred (with regards to reaction time). A significant DAY effect would indicate that either the decrement in accuracy and/or reaction time changed over the course of the five days of the study.

In addition to this analysis of vigilance and latency decrement, two $2 \times 5 \times 2$ TASK $x$ (DAY $x$ BLOCK) repeated measures ANOVAs evaluated the decrements using the Block 1 and Block 5 data directly as opposed to the difference value (Block 1- Block 5) used above. 
Another $2 \times 5 \times 5$ TASK $\times($ DAY $\times$ BLOCK) repeated measures ANOVA was more exploratory in nature. It determined if the number of false alarms varied as a function of the independent variables.

Unpracticed Task. The unpracticed task performance measures for Day 1 and Day 5 were also evaluated to see if they demonstrated improved measures of performance. Three $2 \times 2$ TASK $\times$ (DAY) repeated measures ANOVAs (one for each dependent variable: reaction time, accuracy, and false alarms) were conducted on the unpracticed task data (Day 1 vs. Day 5) to evaluate improvement. Two $2 \times 5$ TASK $\times$ (DAY) repeated measures ANOVAs were conducted to evaluate the vigilance decrement and latency decrement. The decrements were computed by subtracting Block 5 from Block 1 (performance during first 3 minutes - performance during last three minutes) for each performance measure (reaction time and accuracy) for Day 1 and Day 5.

Finally, the reliability of the CPT as a measure of attention was evaluated by examining the consistency of a individual's repeated performance across test sessions. This was accomplished by examining the Pearson's $\mathrm{r}$ correlations within each task across days.

\section{RESULTS}

Exploratory data analysis revealed that the underlying assumptions of independence, normality, homogeneity of variance, and sphericity were not seriously compromised. Effect sizes related to the following statistical tests represent the partial eta $^{2}$ value computed by SPSS. 


\section{Effects of Practice}

Effects of Practice for Repeated Tasks. Table 1 and Figures $1 \& 2$ summarize the reaction time and accuracy data for the repeated tasks. The $2 \times 5 \times 5$ TASK $x$ (DAY $x$ BLOCK) ANOVA for practice effect ( see Tables $2 \& 3$ ) resulted in a significant main effect of DAY for reaction time $(\underline{F}(4,104)=3.00, \underline{p}<.05, E S=.103)$, and a main effect of BLOCK for both reaction time $(\underline{F}(4,104)=36.92, \underline{p}<.05, E S=.587)$ and accuracy $(\underline{F}(4,104)=20.44, \underline{p}<.05, E S=.440)$. There was no significant main effect of TASK, indicating that the type of task (cognitive or sensory) did not significantly influence accuracy or reaction time. There were no significant interaction effects for either dependent variable. The main effects of BLOCK mean that reaction time increased (became slower) and accuracy decreased during the 15 minute span of the test (this will be discussed in more detail in the vigilance and latency decrements section). Follow-up tests for the significant main effect for DAY for reaction time collapsed across tasks and revealed that reaction time on Day $1(\mathrm{M}=652.58 \mathrm{SD}=59.10)$ was significantly slower than reaction time on any other day $(\mathrm{M} 2=625.51 \mathrm{SD}=52.15, \mathrm{M} 3=629.77 \mathrm{SD}=63.69$, $\mathrm{M} 4=622.63 \mathrm{SD}=67.97 \mathrm{M} 5=620.45 \mathrm{SD}=75.79$, respectively) (see Figure 3).

Vigilance and Latency Decrements for Repeated Tasks. These analyses used a computed decrement value as specified in the data analysis portion of the methodology section. Vigilance and latency decrement data are summarized in Table 4 and Figures 4 \& 5. For each dependent variable (vigilance decrement and latency decrement), a $2 \times 5$ TASK $x(D A Y)$ repeated measures ANOVA was conducted (see Tables $5 \& 6$ ). Neither ANOVA produced significant results, indicating that although vigilance decrements did occur (based on the significant BLOCK effect noted in the previous section), the daily 
decrements did not change enough relative to each other to be considered significant. This means that the magnitude of the decrements did not significantly differ across days or tasks. The average daily vigilance decrement was $13.0 \%$ for the letter task, and $10.85 \%$ for the tone task. The average daily latency decrement was $65.18 \mathrm{~ms}$ for the letter task, and $55.28 \mathrm{~ms}$ for the tone task.

The $2 \times 5 \times 2$ TASK $\times$ (DAY $\times$ BLOCK) repeated measures ANOVAs for vigilance decrement and latency decrement follow up on the significant BLOCK effect reported under the "Effects of Practice" heading. The focus of interest is on the change in performance that occurs between the beginning and end of the task, thus this analysis only included blocks 1 and 5 (raw data). The ANOVAs produced two significant main effects findings. Vigilance and latency decrement data are summarized in Table 4 and Figures 4 \& 5. For latency decrement (see Table 7) there was a significant effect of BLOCK ( $\underline{F}$ $(1,26)=61.11, \mathrm{p}<.05, \mathrm{ES}=.702)$, indicating that overall (regardless of task type) reaction time was significantly faster for Block 1 than for Block 5 . For vigilance decrement (see Table 8) there was also a significant effect of $\operatorname{BLOCK}(\underline{F}(1,26)=35.33, \underline{p}<.05, E S=.576)$, indicating that overall (regardless of task type) accuracy was higher for Block 1 than for Block 5 . These findings basically report the same information as was reported above under the heading "Effects of Practice" and support the conclusion that a daily decrement in performance occurred for both reaction time and vigilance for both tasks. The objective of this analysis was to identify a change in decrement in performance, that is, to find a DAY $x$ BLOCK interaction that would indicate that the difference in performance from the beginning of the task to the end of the task changed across the five days of testing. No significant interactions were found. 
False Alarms for Repeated Tasks. The exploratory $2 \times 5 \times 5$ TASK x (DAY x BLOCK) repeated measures ANOVA for number of false alarms produced no significant results, indicating that the number of false alarms did not significantly vary across tasks, days, or the 15 minute length of each test (see Table 9 and Figure 6). Summary data for false alarms are provided in Table 10.

Performance on Unpracticed Tasks After Practicing on a Different Task. The unpracticed task (Day 1 and Day 5 only) data (see Table 11) were analyzed using three separate $2 \times 2$ TASK $\times$ (DAY) repeated measures ANOVAs, one for each of the performance measures (number of false alarms were included here even though they were analyzed separately for the repeated task). For reaction time (see Table 12), there were no significant results, indicating that reaction time did not significantly differ depending on the type of task or the day of the test. For accuracy (see Table 13), there was a significant main effect of TASK, $(\underline{F}(1,26)=18.66, \underline{p}<.05, E S=.418)$. This indicated that the overall level of accuracy was significantly higher for the letter task $(M=92.27 \% \mathrm{SD}=7.57)$ than it was for the tone task $(M=75.70 \% \mathrm{SD}=16.17)$. For false alarms (see Table 14), the ANOVA produced significant main effects of TASK $(\underline{\mathrm{F}}(1,26)=9.11, \underline{\mathrm{p}}<.05, \mathrm{ES}=.259)$ and $\operatorname{DAY}(\underline{\mathrm{F}}(1,26)=18.35, \underline{p}<.05, \mathrm{ES}=.414)$ as well as for the TASK $\times$ DAY interaction $(\underline{F}(1,26)=15.70, \underline{p}<.05, E S=.376)$. The main effect of TASK indicated that overall the tone task produced more false alarms $(\mathrm{M}=27.92 \mathrm{SD}=37.49)$ than did the letter task $(\mathrm{M}=5.29 \mathrm{SD}=3.96)$. The main effect of DAY indicated that regardless of task, more false alarms were committed on the Day $1(\mathrm{M}=22.57 \mathrm{SD}=35.11)$ than on Day $5(\mathrm{M}=7.39 \mathrm{SD}=$ 11.13). This main effect is an important result in that it indicates that performance on one task improved from one administration to the next while the intervening practice was on 
the different task. That is, performance on one task benefited from practice on the other task. Follow up simple effects tests for the interaction effect examined each task across days. The results showed a significant effect of TASK on Day $1(\underline{F}(1,26)=11.71, \underline{p}<.05)$, but not on Day $5(\underline{F}(1,26)=2.43, \underline{p}>.05)$. This means that on Day 1 , there were significantly more false alarms made during the tone task $(M=44.75 \mathrm{SD}=45.36)$ than during the letter task $(M=5.94 \mathrm{SD}=4.54)$, and on Day 5 the difference in number of false alarms made during both tasks was not significant $(\mathrm{M}=11.08 \mathrm{SD}=16.23, \mathrm{M}=4.63 \mathrm{SD}=3.30$ respectively) (See Figure 7). Therefore, practice on the letter task appeared to reduce the number of false alarms made on the unpracticed tone task

Vigilance and Latency Decrements for Unpracticed Tasks. The vigilance and latency decrements were computed for each subject by subtracting Block 5 from Block 1 (performance during first 3 minutes - performance during last three minutes) on both days for each performance measure (reaction time and accuracy) for each task (see Table 15). For each dependent variable, a 2×2 TASK $\times$ (DAY) repeated measures ANOVA determined whether performance decrements differed significantly across days and tasks. The analysis for reaction time produced no significant differences in latency decrement (see Table 16). This corresponds to the stability of the decrement observed during the repeated tasks. For accuracy, a significant difference was found for vigilance decrement across DAY $(\underline{\mathrm{F}}(1,26)=9.15, \underline{\mathrm{p}}<.05, \mathrm{ES}=.260)$ and TASK $\times \mathrm{DAY}(\underline{\mathrm{F}}(1,26)=4.85, \underline{\mathrm{p}}<.05$, $\mathrm{ES}=.157$ ) (see Table 17). The main effect of DAY indicated a difference in vigilance decrement over the course of the test sessions. Follow up tests for the interaction indicated that the vigilance decrement was not significantly different between tasks on Day $1(\underline{F}(1,26)=.52, \underline{p}>.05)$, but was significant on Day $5(\underline{F}(1,26)=4.85, \underline{p}<.05)$ (see Figure 8). 


\section{$\underline{\text { Reliability }}$}

The reliability of the CPT as a measure of attention was evaluated by examining the consistency of an individual's repeated performance across five test sessions. This was accomplished by examining the performance measures correlations (Pearson's r) within each task across days for the practiced data. Results show that for the tone task (see Table 18), reaction time correlations were significant (.636-.880) across all days. That is, at least $40 \%$ of the variance in each day's reaction time can be explained by each other day. False alarm correlations were also significant (.693-.961) across all days. For false alarms, at least $48 \%$ of the variance for each day is explained by each other day. Accuracy correlations were significant (.523-.900) across days 2-5 only. Day 1 accuracy did not significantly correlate with the accuracy for any other day. For days $2-5$, at least $27 \%$ of accuracy variance is accounted for by each of the other days. All correlations mentioned so far have been positive. These results indicate that there is some reliability for each performance measure when measured across days. In addition, Day 1 and Day 2 reaction times were significantly related to Day 3 accuracy $(-.525$ and -.508$)$. Day 4 reaction time was related to accuracy on Days $3 \& 4(-.553$ and -.527$)$ and Day 5 reaction time was also significantly correlated with Day 4 accuracy (-.556). These negative correlations indicate that as accuracy increases, reaction time decreases (gets faster).

The pattern of significant correlations is slightly different for the letter task (see Table 19). Reaction time correlations were significant between each day and the following day. In other words, correlations were significant for Day $1 \&$ Day 2 (.588), Day $2 \&$ Day 3 (.815), Day 3 \& Day 4 (.874), Day 4 \& Day 5 (.766), and also for Day 2 \& Day 4 (.780). For each significant correlation, the shared variability ranged between $34 \%-72 \%$. 
Accuracy correlations were significant (.639-.835) across all days. That is, at a minimum, $40 \%$ of the variance in each day's accuracy can be explained by each other day. There were only two significant correlations for false alarms: Day 2 \& Day 3 (.584), and Day 3 \& Day $4(.900)$. The amount of variance accounted for was $34 \%$ and $81 \%$ respectively. In addition, Day 5 accuracy was significantly correlated with reaction times on Day 2, Day 3, and Day $4(-.670,-.834$, and -.593$)$. Day 5 reaction time significantly correlated with number of Day 5 false alarms (.587).

\section{DISCUSSION}

There are three main objectives of this study. First, do five days of repeated practice on a vigilance task improve performance across days? Second, does practice on one specific vigilance task facilitate performance on another, similar unpracticed vigilance task? Third, do these two vigilance tasks show good test-retest reliability? Each of these questions will be discussed in light of the results of the statistical analyses.

The effect of practice was investigated by examining the average daily performance measures across days and tasks and also by evaluating the vigilance and latency decrements across days and tasks. In terms of daily performance measures, reaction time improved significantly after Day 1 . That is, reaction time on Day 1 was significantly slower than it was on any other day. Analyses of the decrements in performance was broken down into vigilance decrement (based on changes in accuracy) and latency decrement (based on changes in reaction time). The decrements were also assessed in two slightly different ways. The significant BLOCK effect and subsequent follow up tests revealed that both a vigilance decrement and latency decrement occurred over the 15 minute span of the tasks. The second decrement analysis focused on analyzing changes in 
the magnitude of the decrement by day and task. This analysis revealed that the decrements that did occur remained stable over the course of the days of testing. If a significant difference was found in the BLOCK $x$ DAY interaction, it would have indicated that the amount of the decrement varied by day. If the amount of decrement decreased each day, it may have been indicative of an effect of practice; performance declined less during the 15 minute task with each successive day of practice. This was not, however, a finding in this study.

Practice on one vigilance task significantly improved performance on the other task only in the case of number of false alarms made on the tone task. When subjects were tested for the second time on the tone task after having had five practice sessions on the letter task, they made significantly fewer false alarms than they had during the first test session.

The test-retest reliability of these CPT tasks was analyzed by examining the correlations by task for each performance measure across the five days of repeated testing. The pattern of significant correlations leads to the conclusion that both tasks have good reliability. Within each task, the significant correlations for each performance measure across days are illustrative of good construct validity. There is some evidence for convergence in that both the letter and the tone task showed this general pattern. The fact that there are few significant correlations between performance measures supports the idea of divergence; each performance measure is measuring a different aspect of response to a target stimuli. For the tone task, performance measures were highly related across days, with one exception being accuracy on Day 1 , which did not significantly correlate with accuracy on any other day. This finding may be explained by considering that the tone 
task is a more difficult task (based on lower overall accuracy and the tone being a more novel stimulus) and this may affect initial performance on Day 1.

This study did not find the differences in performance, specifically in vigilance decrement between cognitive and sensory CPTs, that have been reported in the literature. Based on results reported in the literature, it was expected that there would be a significant TASK $\mathrm{x}$ DAY or TASK $\mathrm{x}$ BLOCK interaction indicating that performance changed over time differently for the cognitive task that it did for the sensory task (Binford and Loeb, 1966; Koelega et al., 1989; See et al., 1995; Warm 1984; Williams, 1986). Possible reasons for this disagreement with the literature will be discussed shortly. The overall conclusions from this study are that under these conditions, with the exception of reaction time, vigilance performance did not vary due to repeated practice or type of task. Support for the similarity of performance across tasks is provided by Reeve (1997), who conducted a study comparing performance on the same letter and tone tasks described here. One objective of that study was to evaluate the construct validity of the $\mathrm{CPT}$ as a measure of sustained attention. The conclusions from that study are that although some significant differences were found between the two tasks, the two versions of the CPT are relatively equivalent (Reeve, 1997). Results of the vigilance decrement analysis in that study revealed a parallel vigilance decrement for the two tasks. These significant vigilance decrements were also found in this study.

There are several plausible explanations for the lack of significant findings in this study. First, and most straight forward, is the claim by Halperin et al. (1991) that the CPT is resistant to practice effects. Koelega et al. (1989) found that their CPT results indicated that humans are very capable of sustaining attention at a very high level and without false 
alarms for tasks that they consider to be easy and boring. Speeding up the presentation of stimuli would make the tasks more challenging. Koelega et al. (1989) also note that "performance is near optimal when critical targets are coded in well-learned letters" (p. 58). The results of this study lend support to this statement. On the other hand, the consistently, extremely high accuracy performance and relatively low number of false alarms may confound the analysis in that there was little room for improvement in performance. Reducing the onset-to-onset time of the stimuli may also help alleviate this problem.

See et al. (1995) list several factors that could influence the subjects' willingness to respond to targets. These factors include the individual's detection goals, their expectations about the nature and occurrence of the stimuli, and the anticipated consequences of correct and incorrect responses. Their point is that the observable vigilance decrement may be due to more than just a sensitivity decrement. In this study it was not possible to control for many of these nonperceptual factors. Participants were not paid nor were they given daily feedback on performance. The 15 minute tasks are long, and after several days of testing, it is possible that some individual's motivation with regards to the factors mentioned above may have declined. The overall decrease in accuracy across the five test sessions supports this possibility.

Related to these factors are basic individual differences. Koelega (1996) noted that "it is one of the more common findings of research on vigilance that considerable variation exists among performance scores achieved by different individuals working at the same task. Some monitors suffer a considerable loss in proficiency, but others maintain a high performance level throughout the task" (p. 285). The within-subjects design 
employed in this study is an important method for minimizing individual differences. Individual behavioral characteristics are uncontrollable in this situation. Koelega (1996) reports that current research efforts in sustained attention are trying to develop methods to control for these variables.

In summary, performance did not significantly improve after repeated testing with the exception that reaction time improved after Day 1. Improvements in number of false alarms made on Day 5 of the unpracticed tone task indicate that some benefit was gained from practice on the repeated task. Very few differences in vigilance performance were found with regards to the cognitive stimuli-sensory stimuli dimension. The CPT tasks appear to be reliable in that the performance measures had significant correlations across repeated administrations of the tasks. 


\section{REFERENCES}

Binford, J., \& Loeb, M. (1966). Changes within and over repeated sessions in criterion and effective sensitivity in an auditory vigilance task. Journal of Experimental Psychology, 72, 339-345.

Davies, D.R., \& Parasuraman, R. (1982). The psychology of vigilance. New York: Academic Press.

Fisk, A., \& Scerbo, M. (1987). Automatic and control processing approach to interpreting vigilance performance: A review and reevaluation. Human Factors, $29(6), 653-660$.

Halperin, J.M., Sharma, V., Greenblatt, E., \& Schwartz, S. (1991). Assessment of the continuous performance test: Reliability and validity in a nonreferred sample. Psychological Assessment: A Journal of Consulting and Clinical Psychology, 3(4), 603-608.

Koelega, H. (1996). Sustained attention. In O. Neumann and A. F. Sanders (Eds.), Handbook of perception and action, volume 3: Attention (pp. 277-331). New York: Academic Press.

Koelega, H., Brinkman, J., Hendricks, L., \& Verbaten, M. (1989). Processing demands, effort, and individual differences in four different vigilance tasks. Human Factors, $31(1), 45-62$.

Leek, M., \& Watson, C. (1988). Auditory perceptual learning of tonal patterns. Perception and Psychophysics, 43(4), 389-394. 
Neisser, U., \& Hirst, W. (1974). Effect of practice on the identification of auditory sequences. Perception \& Psychophysics, 15(2), 391-398.

Nickerson, R.S., \& Freeman, B. (1974). Discrimination of the order of the components of repeating tone sequences: Effects of frequency separation and extensive practice. Perception \& Psychophysics, 16(3), 471-477.

Parasuraman, R., \& Davies, D. (1977). A taxonomic analysis of vigilance performance. In R.R. Mackie (Ed.), Vigilance: theory, operational performance, and physiological correlates (pp. 559-574). New York: Plenum.

Reeve, N.J. (1997). A comparison of continuous performance tasks using cognitive versus sensory stimuli. Unpublished master's thesis, University of Rhode Island.

Schneider, W., and Fisk, A. D. (1982). Degree of consistent training: Improvements in search performance and automatic process development. Perception and Psychophysics, 31, 160-168.

See, J., Howe, S., Warm, J., \& Dember, W. (1995). Meta-analysis of the sensitivity decrement in vigilance. Psychological Bulletin, 117, 230-249.

Swets, J.A. \& Kristofferson, A.B. (1970). Attention. Annual Review of Psychology, 21, 339-366.

Warm, J. S. (1984). An introduction to vigilance. In D.H. Holding (Series Ed.) \& J.S. Warm (Vol. Ed.), Wiley series on studies in human performance: vol 4. Sustained attention in human performance (pp. 1-14). New York: John Wiley \& Sons, Ltd. Williams, P. (1986). Processing demands, training, and the vigilance decrement. Human Factors, 28(5), 567-579. 
Table 1.

Practiced Task Reaction Time and Accuracy Means and Standard Deviations for Day and Block by Task

\begin{tabular}{lrrrrr} 
LETTERS N=12 & \multicolumn{6}{c}{ Mean Reaction Time (ms) } & \\
& Block 1 & Block 2 & Block 3 & Block 4 & Block 5 \\
Day 1 & 612.04 & 658.27 & 669.96 & 695.25 & 672.04 \\
Day 2 & 604.63 & 652.18 & 660.49 & 660.37 & 667.03 \\
Day 3 & 612.60 & 631.92 & 664.76 & 681.53 & 666.57 \\
Day 4 & 592.47 & 630.25 & 656.14 & 655.92 & 667.64 \\
Day 5 & 602.74 & 655.69 & 657.84 & 656.53 & 677.10 \\
& & & & & \\
Block M & 604.90 & 645.66 & 661.84 & 669.92 & 670.08 \\
SD & 58.44 & 61.95 & 69.22 & 69.50 & 65.18
\end{tabular}

TONES N=16 Mean Reaction Time (ms)

$\begin{array}{lrrrrrrr} & \text { Block 1 } & \text { Block 2 } & \text { Block 3 } & \text { Block 4 } & \text { Block 5 } & \text { Day M } & \text { Day SD } \\ \text { Day 1 } & 628.02 & 656.26 & 650.59 & 640.48 & 653.99 & 645.87 & 69.27 \\ \text { Day 2 } & 569.81 & 595.76 & 612.33 & 627.02 & 643.89 & 609.76 & 67.35 \\ \text { Day 3 } & 580.16 & 604.74 & 632.06 & 622.53 & 635.60 & 615.02 & 77.02 \\ \text { Day 4 } & 564.37 & 618.70 & 621.50 & 636.58 & 628.95 & 614.02 & 91.51 \\ \text { Day 5 } & 565.82 & 594.34 & 600.41 & 619.00 & 622.18 & 600.35 & 84.44\end{array}$

$\begin{array}{lrrrrr}\text { Block M } & 581.64 & 613.96 & 623.38 & 629.12 & 636.92 \\ \text { SD } & 73.63 & 78.29 & 82.71 & 81.28 & 217.93\end{array}$

\begin{tabular}{lrrrrr}
\multicolumn{7}{l}{ LETTERS N=12 } & \multicolumn{3}{c}{ Mean Accuracy (\%) } \\
Block 1 & Block 2 & Block 3 & Block 4 & Block 5 \\
Day 1 & 94.84 & 92.46 & 90.85 & 89.53 & 88.25 \\
Day 2 & 97.08 & 92.06 & 94.10 & 88.28 & 80.18 \\
Day 3 & 91.95 & 89.08 & 82.69 & 83.11 & 81.64 \\
Day 4 & 95.83 & 93.33 & 81.64 & 84.26 & 78.53 \\
Day 5 & 96.64 & 92.37 & 82.43 & 84.05 & 82.76 \\
Block M & 95.27 & 91.86 & 86.34 & 85.85 & 82.27 \\
SD & 8.37 & 11.97 & 17.95 & 15.09 & 17.27
\end{tabular}

\begin{tabular}{lrrrrrrr} 
TONES & \multicolumn{1}{c}{ N=16 } & \multicolumn{2}{c}{ Mean Accuracy (\%) } & & & & \\
& Block 1 & Block 2 & Block 3 & Block 4 & Block 5 & Day M & Day SD \\
Day 1 & 94.06 & 88.75 & 86.88 & 82.50 & 82.88 & 87.01 & 13.52 \\
Day 2 & 96.56 & 93.13 & 92.19 & 89.69 & 85.21 & 91.36 & 11.74 \\
Day 3 & 95.00 & 92.81 & 90.94 & 88.44 & 86.03 & 90.64 & 13.62 \\
Day 4 & 92.81 & 91.25 & 84.38 & 85.94 & 86.32 & 88.14 & 17.71 \\
Day 5 & 93.13 & 92.50 & 84.38 & 80.31 & 76.88 & 85.44 & 21.11
\end{tabular}

$\begin{array}{llllll}\text { Block M } & 94.31 & 91.69 & 87.75 & 85.38 & 83.46 \\ \text { SD } & 11.95 & 12.43 & 14.30 & 18.91 & 18.72\end{array}$

Note: $\mathrm{M}=$ mean, $\mathrm{SD}=$ standard deviation, $\mathrm{ms}=$ milliseconds 
Table 2.

ANOVA Summary Table for $2 \times 5 \times 5$ TASK $\times$ (DAY x BLOCK) Analysis for Reaction Time

$\begin{array}{lrrrrc}\text { N=28 } & \text { DF } & \text { SS } & \text { MS } & \text { F } & \text { P } \\ \text { TASK } & 1 & 192091.3 & 192091.3 & 2.50 & 0.126 \\ \text { ERROR } & 26 & 1999238.0 & 76893.8 & & \\ \text { DAY } & 4 & 73112.8 & 18278.2 & 3.00 & 0.022 * \\ \text { TASK x DAY } & 4 & 22953.8 & 5738.5 & 0.94 & 0.443 \\ \text { DAY x ERROR } & 104 & 633628.9 & 6092.59 & & \\ & & & & & \\ \text { BLOCK } & 4 & 325246.9 & 81311.7 & 36.92 & 0.001 \text { * } \\ \text { TASK x BLOCK } & 4 & 6378.1 & 1594.5 & 0.72 & 0.577 \\ \text { BLOCK x ERROR } & 104 & 229050.7 & 2202.41 & & \\ & & & & & \\ \text { DAY x BLOCK } & 16 & 16938.8 & 1058.7 & 0.73 & 0.768 \\ \text { TASK x DAY } x \text { BLOCK } & 16 & 28633.5 & 1789.6 & 1.23 & 0.243 \\ \text { DAY X BLOCK x ERROR } & 416 & 606473.9 & 1457.87 & & \end{array}$

$*=\mathrm{p}<.05$ 
Table 3.

ANOVA Summary Table for $2 \times 5 \times 5$ TASK x (DAY x BLOCK) Analysis for Accuracy

$\mathrm{N}=28$

TASK

ERROR

DAY

TASK $\times$ DAY

DAY $\times$ ERROR

BLOCK

TASK $\times$ BLOCK

BLOCK $\times$ ERROR

DAY $\times$ BLOCK

TASK $\times$ DAY $\times$ BLOCK

DAY $x$ BLOCK $x$ ERROR

$\begin{array}{rrrrr}\text { DF } & \text { SS } & \text { MS } & \text { F } & \text { P } \\ & & & & \\ 1 & 6.82 & 6.82 & 0 & 0.958 \\ 26 & 63478.4 & 2441.48 & & \\ & & & & \\ 4 & 1497.5 & 374.4 & 1.15 & 0.337 \\ 4 & 1703.0 & 425.7 & 1.31 & 0.272 \\ 104 & 33854.44 & 325.52 & & \end{array}$

$\begin{array}{rrrrr}4 & 12678.5 & 3169.6 & 20.44 & 0.001 \text { * } \\ 4 & 149.7 & 37.4 & 0.24 & 0.914 \\ 104 & 16127.53 & 155.07 & & \end{array}$

$\begin{array}{lllll}16 & 1823.3 & 114.0 & 1.23 & 0.242\end{array}$

$\begin{array}{lllll}16 & 1082.0 & 67.6 & 0.73 & 0.764\end{array}$

$\begin{array}{lll}416 & 38572.1 & 92.7\end{array}$

$*=p<.05$ 
Table 4.

Practiced Task Latency Decrement and Vigilance Decrement Summary Data for Day and Block by Task

\begin{tabular}{|c|c|c|c|c|}
\hline \multirow{2}{*}{\multicolumn{2}{|c|}{$\begin{array}{l}\text { LETTERS } \\
\mathrm{N}=12\end{array}$}} & \multicolumn{2}{|c|}{ Mean Reaction Time (ms) } & \multirow{2}{*}{$\begin{array}{l}\text { Latency } \\
\text { Decrement }\end{array}$} \\
\hline & & Block 1 & Block 5 & \\
\hline & Day 1 & 612.04 & 672.04 & -59.99 \\
\hline & Day 2 & 604.63 & 667.03 & -62.41 \\
\hline & Day 3 & 612.60 & 666.57 & -53.96 \\
\hline & Day 4 & 592.47 & 667.64 & -75.17 \\
\hline & Day 5 & 602.74 & 677.10 & -74.37 \\
\hline & Block M & 604,90 & 670.08 & -65.18 \\
\hline & SD & 58.44 & 65.18 & \\
\hline \multirow{9}{*}{$\begin{array}{l}\text { TONES } \\
N=16\end{array}$} & & \multicolumn{2}{|c|}{ Mean Reaction Time (ms) } & Latency \\
\hline & & Block 1 & Block 5 & Decrement \\
\hline & Day 1 & 628.02 & 653.99 & -25.97 \\
\hline & Day 2 & 569.81 & 643.89 & -74.08 \\
\hline & Day 3 & 580.16 & 635.60 & -55.44 \\
\hline & Day 4 & 564.37 & 628.95 & -64.58 \\
\hline & Day 5 & 565.82 & 622.18 & -56.35 \\
\hline & Block M & 581.64 & 636.92 & -55.28 \\
\hline & SD & 70.33 & 84.21 & \\
\hline \multirow{2}{*}{\multicolumn{2}{|c|}{$\begin{array}{l}\text { LETTERS } \\
\mathrm{N}=12\end{array}$}} & \multicolumn{2}{|c|}{ Mean Accuracy (\%) } & Vigilance \\
\hline & & Block 1 & Block 5 & Decrement \\
\hline & Day 1 & 94.84 & 88.25 & 6.59 \\
\hline & Day 2 & 97.08 & 80.18 & 16.91 \\
\hline & Day 3 & 91.95 & 81.64 & 10.31 \\
\hline & Day 4 & 95.83 & 78.53 & 17.30 \\
\hline & Day 5 & 96.64 & 82.76 & 13.88 \\
\hline & Block $\mathbf{M}$ & 95.27 & 82.27 & 13.00 \\
\hline & SD & 8.37 & 17.27 & \\
\hline \multirow{9}{*}{$\begin{array}{l}\text { TONES } \\
N=16\end{array}$} & & \multicolumn{2}{|c|}{ Mean Accuracy (\%) } & Vigilance \\
\hline & & Block 1 & Block 5 & Decrement \\
\hline & Day 1 & 94.06 & 82.88 & 11.19 \\
\hline & Day 2 & 96.56 & 85.21 & 11.35 \\
\hline & Day 3 & 95.00 & 86.03 & 8.97 \\
\hline & Day 4 & 92.81 & 86.32 & 6.49 \\
\hline & Day 5 & 93.13 & 76.88 & 16.25 \\
\hline & Block M & 94.31 & 83.46 & 10.85 \\
\hline & SD & 11.95 & 18.72 & \\
\hline
\end{tabular}

Note: $\mathrm{M}=$ mean, $\mathrm{SD}=$ standard deviation, $\mathrm{ms}=$ milliseconds 
Table 5.

ANOVA Summary Table for $2 \times 5$ TASK x (DAY) Analysis for Vigilance Decrement

$\mathrm{N}=28$

TASK

ERROR

DAY

TASK $\times$ DAY

DAY $\times$ ERROR

$*=p<.05$
DF

SS

MS

F

P

$\begin{array}{lll}1 & 158.2 & 158.2\end{array}$

$\begin{array}{lll}26 & 14348.9 & 551.9\end{array}$

$\begin{array}{lll}4 & 800,1 & 200.0\end{array}$

0.72

0.580

$\begin{array}{lll}4 & 1049.9 & 262.5\end{array}$

$104 \quad 28855.5 \quad 277.5$

$0.95 \quad 0.441$ 
Table 6.

ANOVA Summary Table for $2 \times 5$ TASK x (DAY) Analysis for Latency Decrement

$\mathrm{N}=28$

TASK

ERROR

DAY

TASK $\times$ DAY

DAY $x$ ERROR
DF

$\begin{array}{rrr}1 & 3357.4 & 3357.4 \\ 26 & 211675.4 & 8141.4\end{array}$

$4 \quad 14033.6 \quad 3508.4$

$4 \quad 8525.5 \quad 2131.4$

$104 \quad 379633.1 \quad 3650.3$
MS

F

0.41

0.526

0.96

0.432

0.58

0.675

$*=p<.05$ 
Table 7.

ANOVA Summary Table for $2 \times 5 \times 2$ TASK x (DAY x BLOCK) Analysis for Latency Decrement

$\begin{array}{lrrrrr}\text { N=28 } & \text { DF } & \text { SS } & \text { MS } & \text { F } & \text { P } \\ \text { TASK } & 1 & 54563.5 & 54563.5 & 1.91 & 0.179 \\ \text { ERROR } & 26 & 742230.5 & 28547.3 & & \\ \text { DAY } & 4 & 26061.7 & 6515.4 & 2.22 & 0.072 \\ \text { TASK x DAY } & 4 & 14974.2 & 3743.6 & 1.27 & 0.285 \\ \text { DAY x ERROR } & 104 & 305720.3 & 2939.62 & & \\ \text { BLOCK } & 1 & 248767.6 & 248767.6 & 61.11 & 0.001 * \\ \text { TASK x BLOCK } & 1 & 1678.7 & 1678.7 & 0.41 & 0.526 \\ \text { BLOCK x ERROR } & 26 & 105837.7 & 4070.68 & & \\ & & & & & \\ \text { DAY x BLOCK } & 4 & 7016.8 & 1754.2 & 0.96 & 0.432 \\ \text { TASK x DAY x BLOCK } & 4 & 4262.8 & 1065.7 & 0.58 & 0.675 \\ \text { DAY x BLOCK x ERROR } & 104 & 189816.6 & 1825.16 & & \end{array}$

$*=\mathrm{p}<.05$ 
Table 8.

ANOVA Summary Table for $2 \times 5 \times 2$ TASK $\times$ (DAY x BLOCK) Analysis for Vigilance Decrement

$\mathrm{N}=28$

$\mathrm{DF}$

TASK

ERROR

$\begin{array}{rrrrr}1 & 0.9 & 0.9 & 0.00 & 0.972 \\ 26 & 19588.1 & 735.4 & \end{array}$

DAY

TASK $x$ DAY

$\begin{array}{rrrrr}4 & 256.5 & 64.1 & 0.38 & 0.822 \\ 4 & 769.4 & 192.4 & 1.14 & 0.341 \\ 104 & 17512.9 & 168.4 & & \end{array}$

BLOCK

TASK $\times$ BLOCK

$\begin{array}{lllll}1 & 9749.9 & 9749.9 & 35.33 & 0.001 \text { * }\end{array}$

BLOCK $\times$ ERROR

$\begin{array}{lllll}1 & 79.1 & 79.1 & 0.29 & 0.597\end{array}$

$\begin{array}{lll}26 & 7174.4 & 275.9\end{array}$

DAY $\times$ BLOCK

TASK $\times$ DAY $x$ BLOCK

$\begin{array}{lllll}4 & 400.1 & 100.0 & 0.72 & 0.580\end{array}$

DAY $x$ BLOCK $x$ ERROR

$\begin{array}{lllll}4 & 525.0 & 131.2 & 0.95 & 0.441\end{array}$

$*=\mathbf{p}<.05$ 
Table 9.

ANOVA Summary Table for $2 \times 5 \times 5$ TASK $\times$ (DAY x BLOCK) Analysis for False Alarms

$\mathrm{N}=28$

TASK

ERROR

DAY

TASK $\times$ DAY .

DAY $x$ ERROR

BLOCK

TASK $\times$ BLOCK

BLOCK $\times$ ERROR

DAY $x$ BLOCK

TASK $x$ DAY $x$ BLOCK

DAY $x$ BLOCK $x$ ERROR
DF

$\begin{array}{rrr}1 & 2.5 & 2.5 \\ 26 & 945.7 & -36.4\end{array}$

$\begin{array}{lll}26 & 945.7 & -36.4\end{array}$

$\begin{array}{lll}4 & 54.4 & 13.6\end{array}$

$\begin{array}{lll}4 & 50.24 & 12.56\end{array}$

$104 \quad 598.8$

$4 \quad 5.4$

$4 \quad 17.6$

$104 \quad 312.8$

$\begin{array}{ll}16 & 30.3\end{array}$

$16 \quad 17.6$

416
17.6
600.9

1.9

1.1

1.4
$\mathbf{P}$

$\begin{array}{ll}0.07 & 0.794\end{array}$

5.8

$\begin{array}{lll}1.4 & 0.45 & 0.771\end{array}$

$\begin{array}{lll}4.4 & 1.46 & 0.220\end{array}$

3.0

1.31

0.186

0.76

0.729

$*=p<.05$ 
Table 10.

Practiced Task Average Number of False Alarms Made by Day and Block by Task

\section{LETTERS $\mathrm{N}=12$}

$\begin{array}{lrrrrr} & \text { Block 1 } & \text { Block 2 } & \text { Block 3 } & \text { Block 4 } & \text { Block 5 } \\ \text { Day 1 } & 1.00 & 0.33 & 1.00 & 1.00 & 1.42 \\ \text { Day 2 } & 0.58 & 1.50 & 1.50 & 1.17 & 1.17 \\ \text { Day 3 } & 1.00 & 1,33 & 1.00 & 1.25 & 1.33 \\ \text { Day 4 } & 0.83 & 0.75 & 1.67 & 1.83 & 1.17 \\ \text { Day 5 } & 0.33 & 0.08 & 0.75 & 0.83 & 1.00 \\ & & & & & \\ \text { Block M } & 0.75 & 0.80 & 1.18 & 1.22 & 1.22 \\ \text { SD } & 1.11 & 1.40 & 1.73 & 1.58 & 1.43\end{array}$

TONES $\mathrm{N}=16$

$\begin{array}{lrrrrrc} & \text { Block 1 } & \text { Block 2 } & \text { Block 3 } & \text { Block 4 } & \text { Block 5 } & \text { Day (sum of blocks) } \\ \text { Day 1 } & 2.75 & 1.69 & 1.56 & 1.63 & 1.38 & 9.00 \\ \text { Day 2 } & 2.38 & 1.88 & 1.81 & 1.19 & 1.38 & 8.63 \\ \text { Day 3 } & 0.69 & 0.56 & 0.75 & 0.75 & 0.69 & 3.44 \\ \text { Day 4 } & 0.56 & 0.56 & 0.94 & 0.75 & 1.00 & 3.81 \\ \text { Day 5 } & 0.81 & 0.56 & 0.75 & 0.81 & 1.06 & 4.00\end{array}$

$\begin{array}{llllll}\text { Block M } & 1.44 & 1.05 & 1.16 & 1.03 & 1.10 \\ \text { SD } & 3.58 & 2.10 & 1.82 & 1.68 & 1.37\end{array}$

Note: $\mathrm{M}=$ mean, $\mathrm{SD}=$ standard deviation 
Table 11.

Unpracticed Task Means and Standard Deviations for Reaction Time, Accuracy, and False Alarms by Task

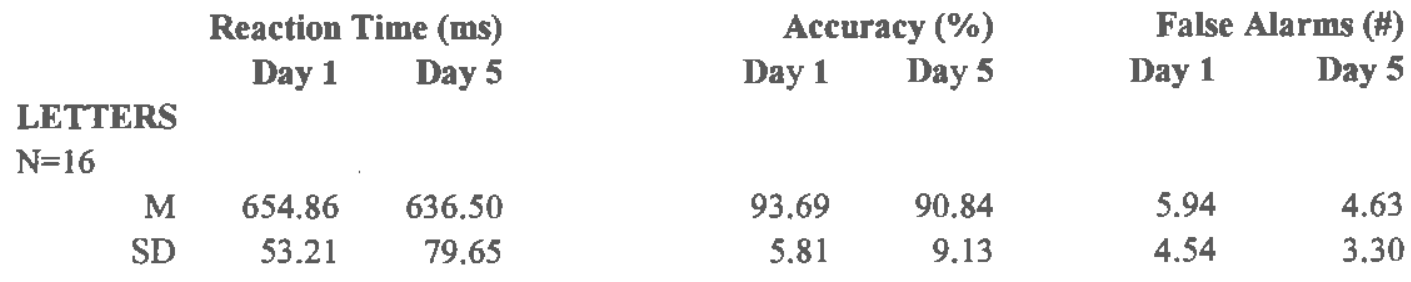

\section{TONES}

$\mathrm{N}=12$

$\begin{array}{rrrrrrr}\mathrm{M} & \mathbf{6 8 2 . 7 8} & \mathbf{6 7 1 . 3 4} & 77.42 & 73.98 & 44.75 & 11.08 \\ \mathrm{SD} & 56.54 & \mathbf{8 7 . 0 8} & 14.50 & 18.17 & 45.36 & 16.23\end{array}$

Note: $\mathrm{M}=$ mean, $\mathrm{SD}=$ standard deviation, $\mathrm{ms}^{=}=$milliseconds 
Table 12.

Unpracticed Task ANOVA Summary Table for 2x2 TASK x (DAY) Analysis for Reaction Time

$\mathrm{N}=28$

$\begin{array}{rrrrr}\text { DF } & \text { SS } & \text { MS } & \text { F } & \text { P } \\ & & & & \\ 1 & 13503.4 & 13503.4 & 1.77 & 0.195 \\ 26 & 198545.3 & 7636.4 & & \end{array}$

DAY

TASK $\times$ DAY

$\begin{array}{rrrrr}1 & 3046.0 & 3046.0 & 1.37 & 0.252 \\ 1 & 164.1 & 164.1 & 0.07 & 0.788 \\ 26 & 57660.8 & 2217.7 & & \end{array}$

$*=p<.05$ 
Table 13.

Unpracticed Task ANOVA Summary Table for 2x2 TASK x (DAY) Analysis

for Accuracy

$\mathrm{N}=28$

$\begin{array}{rrrrr}\text { DF } & \text { SS } & \text { MS } & \text { F } & \text { P } \\ & & & & \\ 1 & 3763.5 & 3763.5 & 18.66 & 0.001 * \\ 26 & 5243.4 & 201.7 & & \\ & & & & \\ 1 & 135.6 & 135.6 & 1.43 & 0.242 \\ 1 & 1.1 & 1.1 & 0.01 & 0.913 \\ 26 & 2459.0 & 94.6 & & \end{array}$

$*=p<.05$ 
Table 14.

Unpracticed Task ANOVA Summary Table for 2x2 TASK x (DAY) Analysis for False Alarms

$\mathrm{N}=28$

TASK

ERROR

DAY

TASK $\times$ DAY

DAY $x$ ERROR
$\mathrm{DF}$

$\begin{array}{lll}1 & 7026.7 & 7026.7\end{array}$

$26 \quad 20060.8 \quad 771.6$

$1 \quad 4195.0 \quad 4195.0$

$\begin{array}{lll}1 & 3589.0 & 3589.0\end{array}$

$\begin{array}{lll}26 & 5945.1 & 228.7\end{array}$

$*=p<.05$ 
Table 15.

Unpracticed Task Mean Reaction Time, Accuracy, and Latency and Vigilance Decrements by Task

$\begin{array}{llrrr}\text { LETTERS } & & \text { Mean Reaction Time (ms) } & \text { Latency } \\ \mathrm{N}=16 & & \text { Block 1 } & \text { Block 5 } & \text { Decremen } \\ & \text { Day 1 } & 589.21 & 678.27 & -89.06 \\ & \text { Day 5 } & 591.95 & 653.91 & -61.96 \\ & \text { Block M } & 590.58 & 666.09 & -75.51 \\ \text { SD } & 81.35 & 74.04 & \end{array}$

TONES

$\mathrm{N}=12$

Day 1
Day 5

Mean Reaction Time (ms)

Block 1 Block 5

$655.62 \quad 681.95$

$638.49 \quad 693.92$

Block M

SD

687.94

$70.33 \quad 84.21$

$\begin{array}{rr}\text { Mean Accuracy(\%) } \\ \text { Block 1 } & \text { Block 5 } \\ 96.53 & 94.69 \\ 92.98 & 87.91 \\ 94.76 & 91.30 \\ 6.63 & 12.12\end{array}$

LETTERS

$\mathrm{N}=16$

Day 1

Day 5

Block M

SD

\section{Mean Accuracy $(\%)$}

Block 1 Block 5

$\mathrm{N}=12$

Day 1

Day 5

80.42

81.05

84.17

64.28

Block M

SD

82.30

17.69

72.67

20.19

$$
\begin{array}{r}
\text { Latency } \\
\text { Decrement } \\
-26.33 \\
-55.42 \\
-40.88
\end{array}
$$

Vigilance

Decrement

1.84

5.07

3.45

Vigilance

Decrement

$-0.63$

19.88

9.63

Note: $\mathrm{M}=$ mean, $\mathrm{SD}=$ standard deviation, $\mathrm{ms}=$ milliseconds 
Table 16.

Unpracticed Task ANOVA Summary Table for $2 \times 2$ TASK x (DAY) Analysis for Latency Decrement

$\mathrm{N}=28$

$\mathrm{DF}$

SS MS

F

$\mathbf{P}$

TASK

$\begin{array}{lll}1 & 16453.8 & 16453.8\end{array}$

$\begin{array}{lll}26 & 139924.8 & 5381.7\end{array}$

ERROR

$\begin{array}{lllll}1 & 13.6 & 13.6 & 0.00 & 0.958\end{array}$

DAY

TASK $\times$ DAY

$1 \quad 10828.4 \quad 10828.4$

$\begin{array}{lll}26 & 122603.7 & 4715.5\end{array}$

DAY $\times$ ERROR

$*=p<.05$ 
Table 17.

Unpracticed Task ANOVA Summary Table for $2 \times 2$ TASK $x$ (DAY) Analysis for Vigilance Decrement

$\mathrm{N}=28$

DF

SS

MS

$\mathbf{F}$

$\mathbf{P}$

TASK

$\begin{array}{lll}1 & 522.4 & 522.4\end{array}$

ERROR

$\begin{array}{lll}26 & 4671.3 & 179.7\end{array}$

DAY

TASK $\mathrm{x}$ DAY

$1 \quad 1933.6 \quad 1933.6$

$1 \quad 1024.4 \quad 1024.4$

DAY $x$ ERROR

$\begin{array}{lll}26 & 5497.1 & 211.4\end{array}$

$*=p<.05$ 
$\frac{4}{2}$

㝒

$\frac{\overleftarrow{c}}{\tilde{c}}$

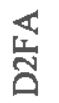

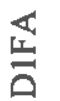

ֻับ

$\underset{\Xi}{8}$

岁

క

延

察

䒓

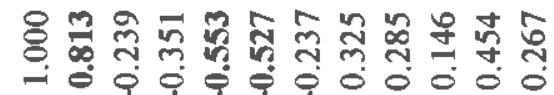

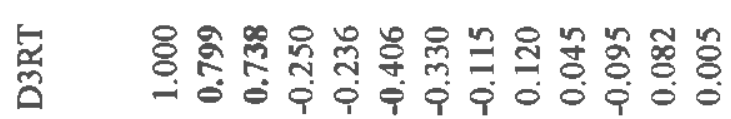

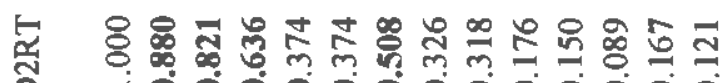

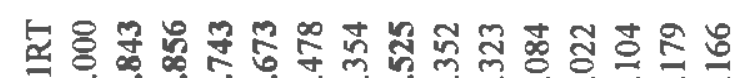
岁

$\infty$ 兽总

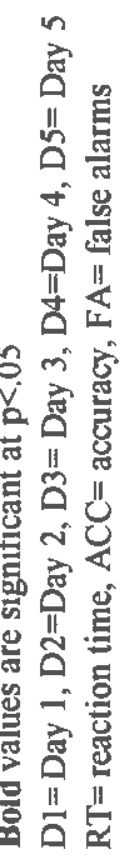

产 
獣

榐

獣

獣

重

玅

䛚

若

ర্ৰ

ह

孚

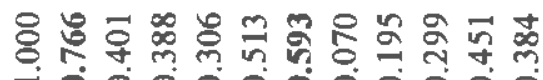

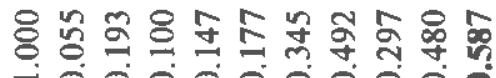

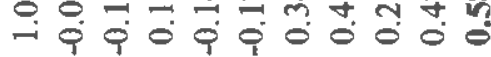

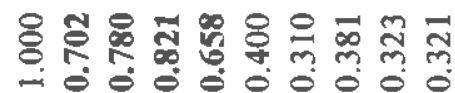

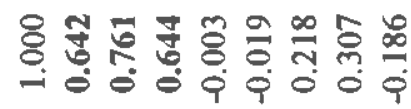

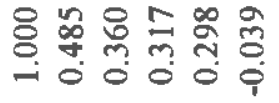

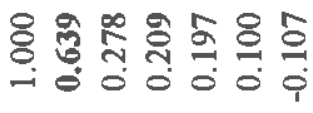

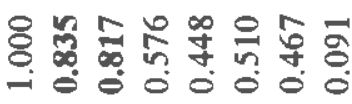


LETTER TASK

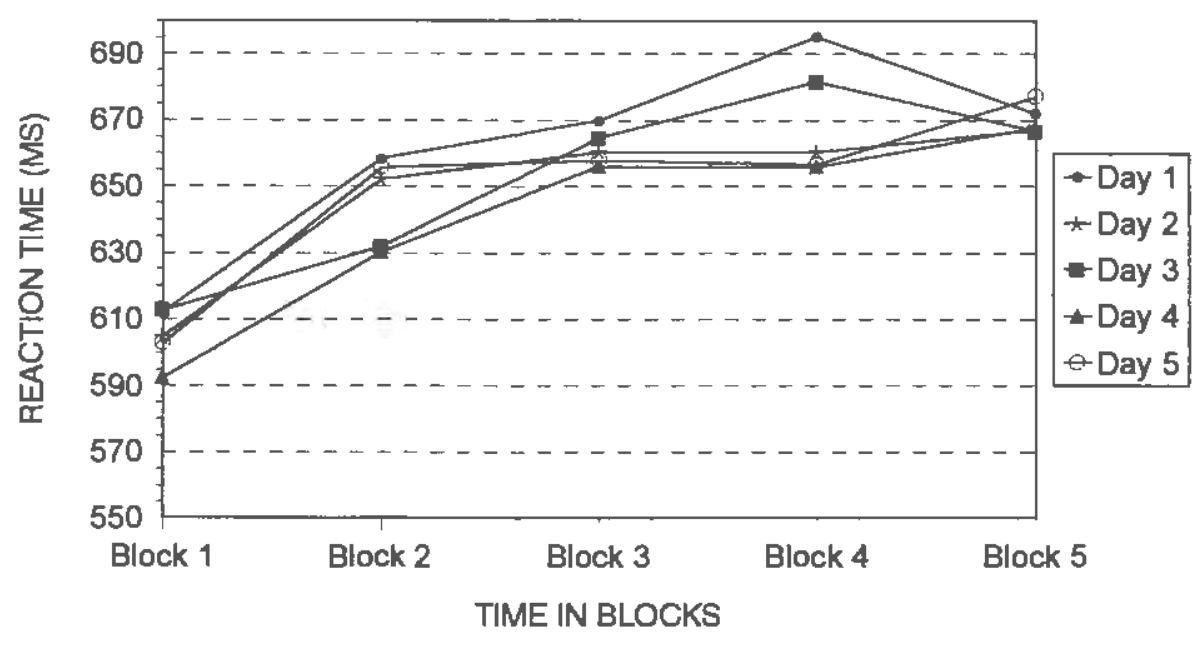

TONE TASK

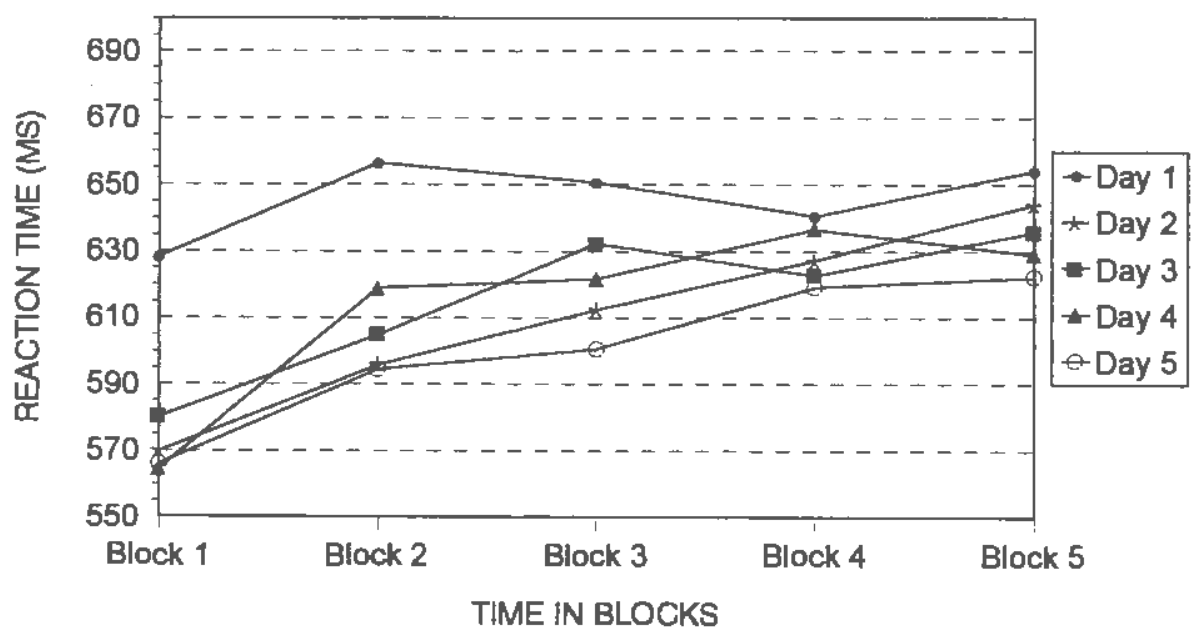

Figure 1. Practiced Task Mean Reaction Time by Day and Block 


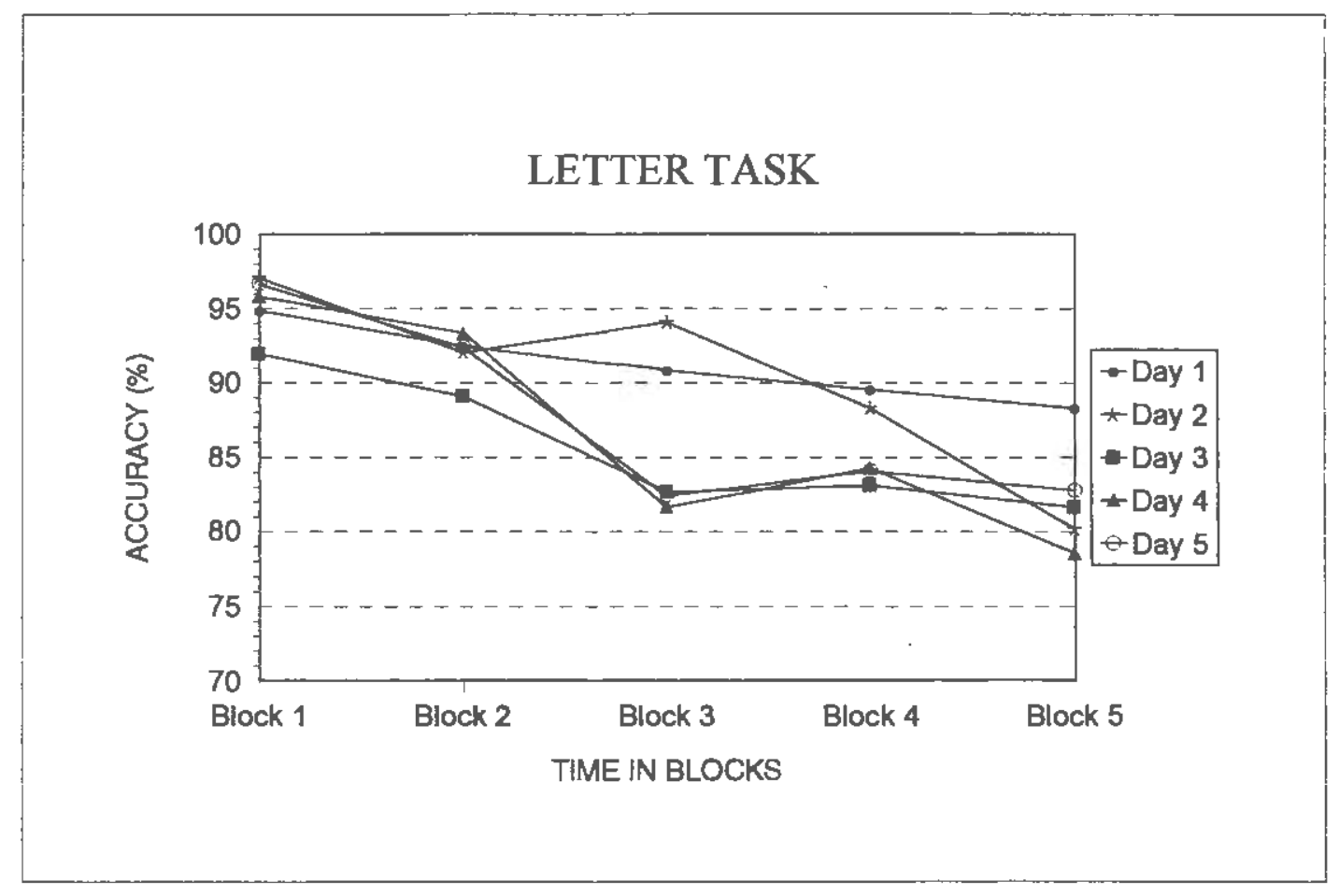

TONE TASK

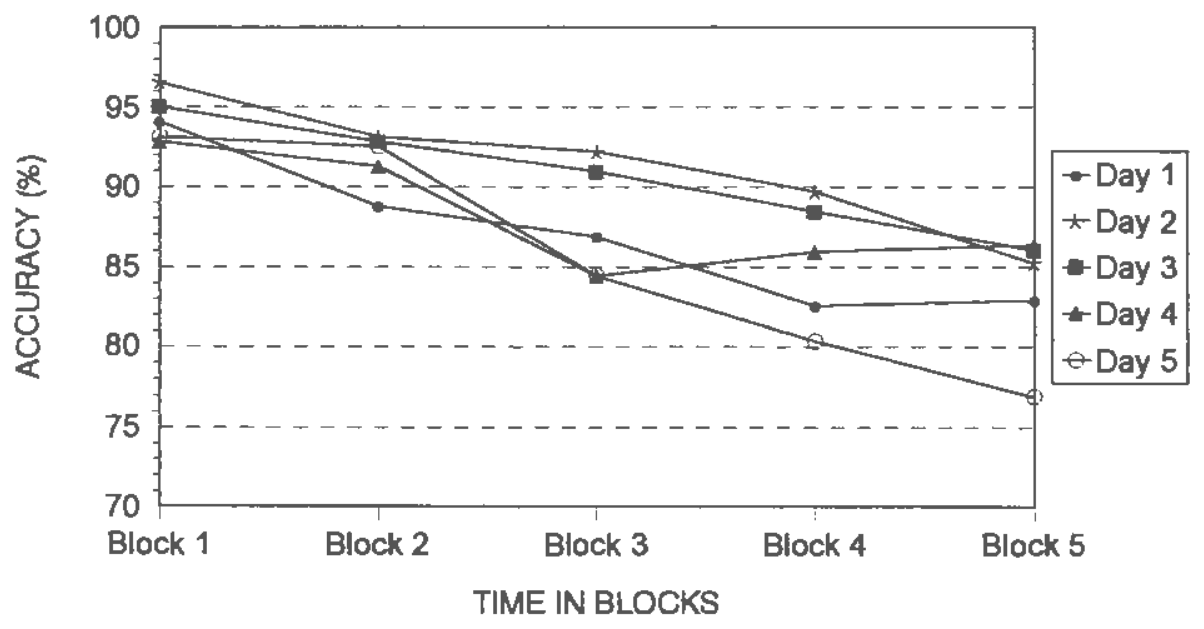

Figure 2. Practiced Task Mean Accuracy by Day and Block 
COMBINED REACTION TIME OVER DAYS

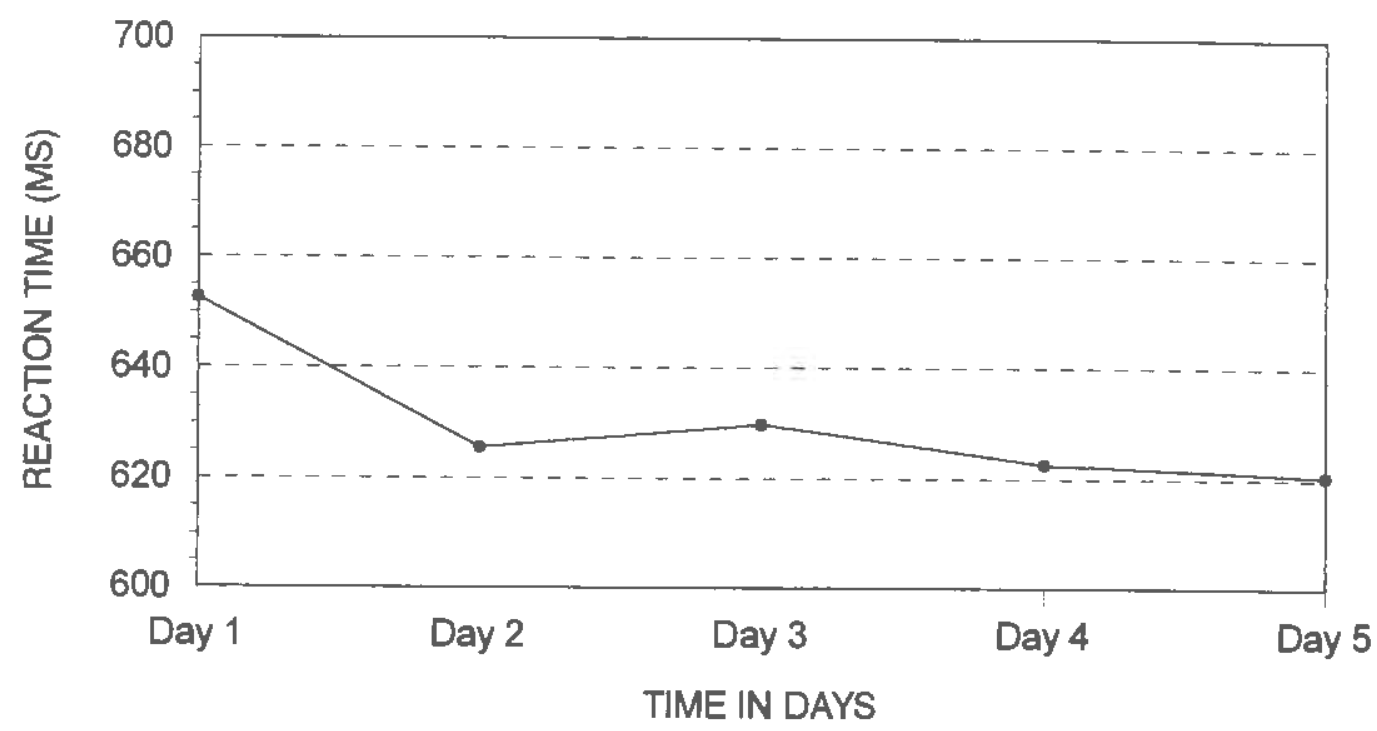

Figure 3. Combined Tasks Mean Reaction Time Across Days 


\section{LETTER TASK}

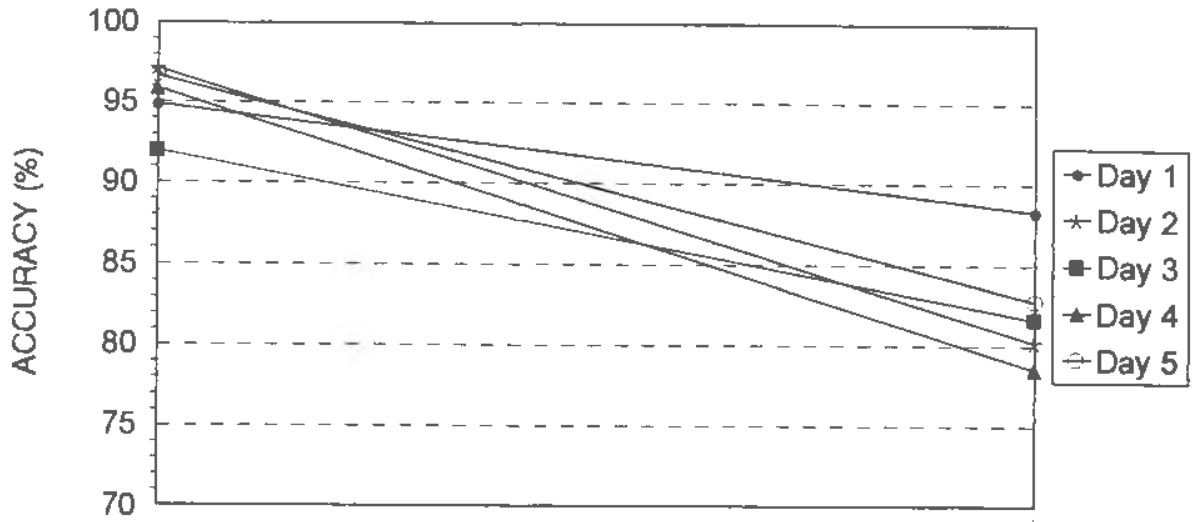

Block 1

Block 5

TIME IN BLOCKS

\section{TONE TASK}

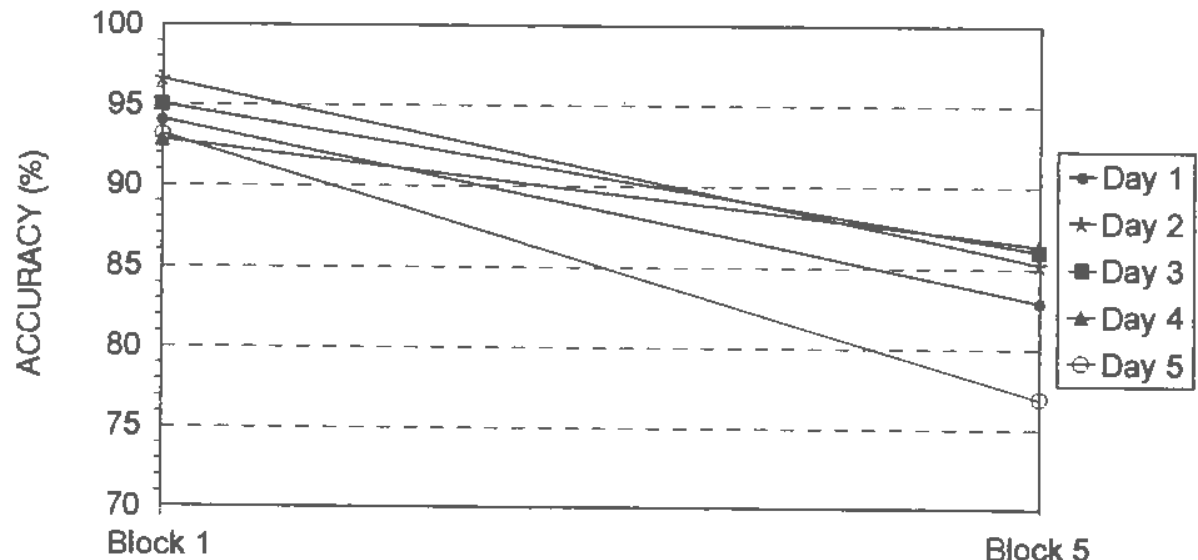

TIME IN BLOCKS

Figure 4. Practiced Task Mean Vigilance Decrement by Day and Block 
LETTER TASK

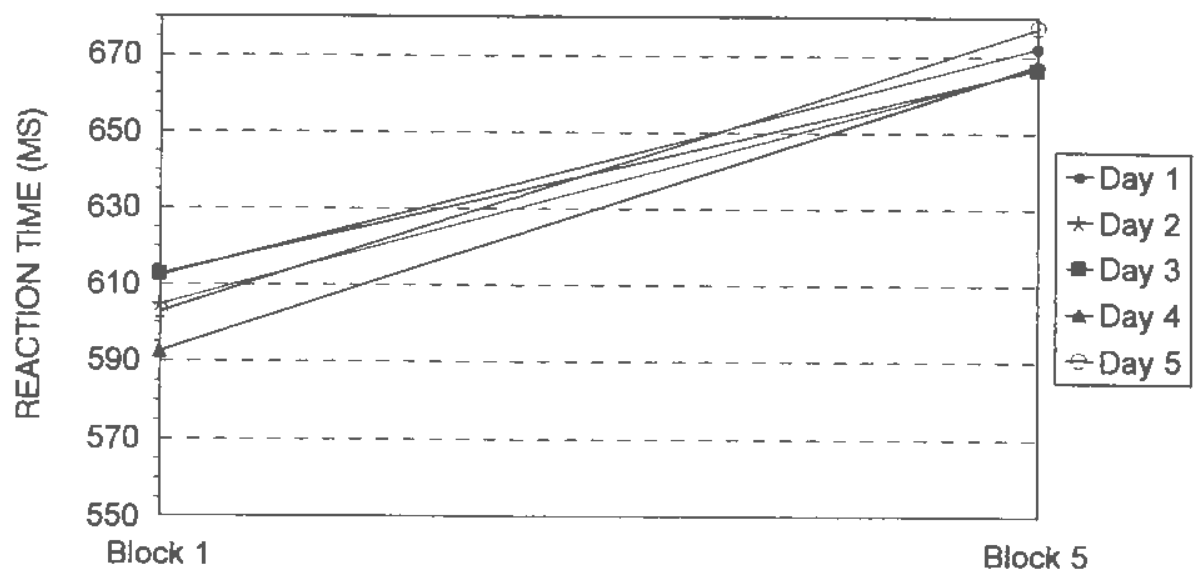

TIME IN BLOCKS

TONE TASK

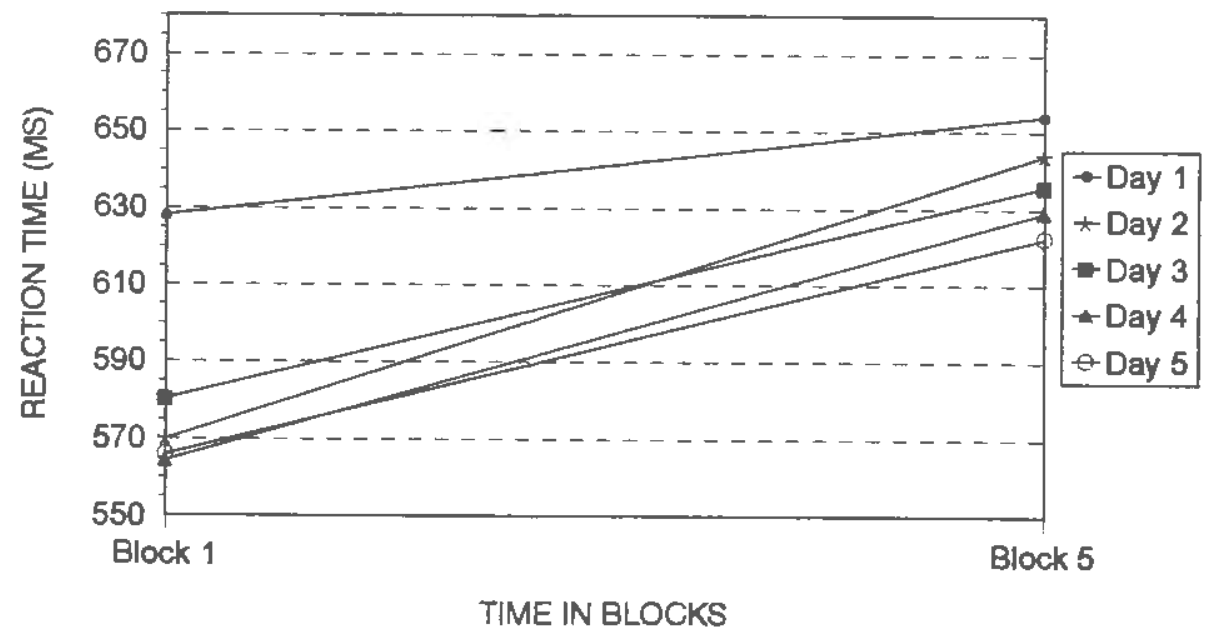

Figure 5. Practiced Task Mean Latency Decrement by Day and Block 


\section{LETTER TASK}

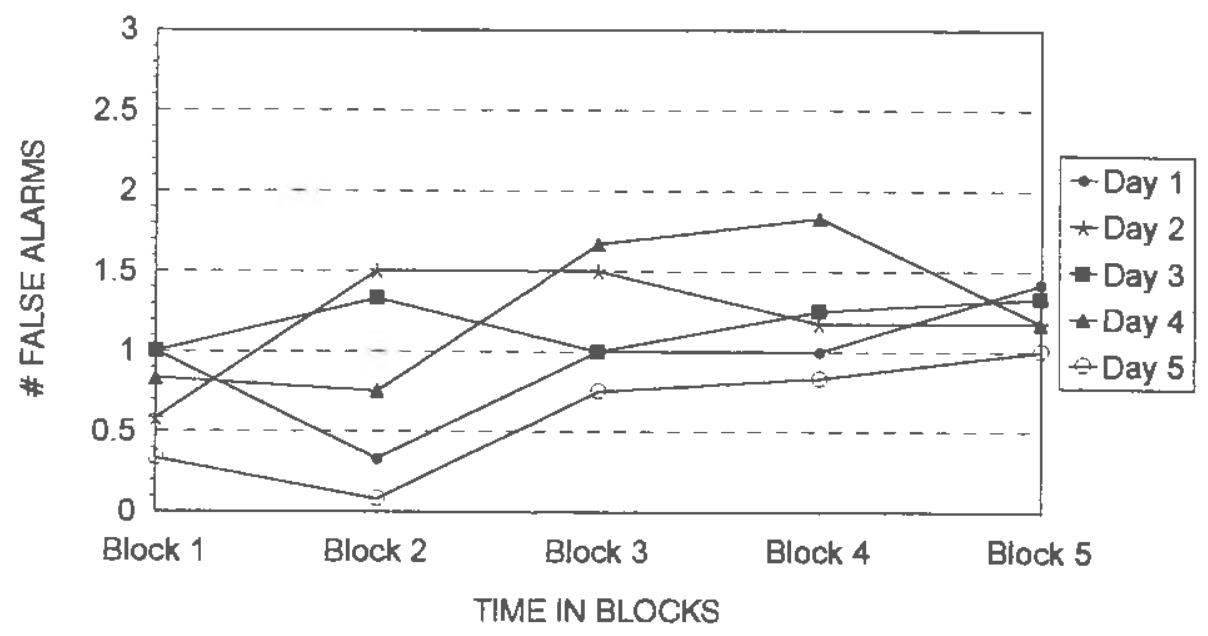

TONE TASK

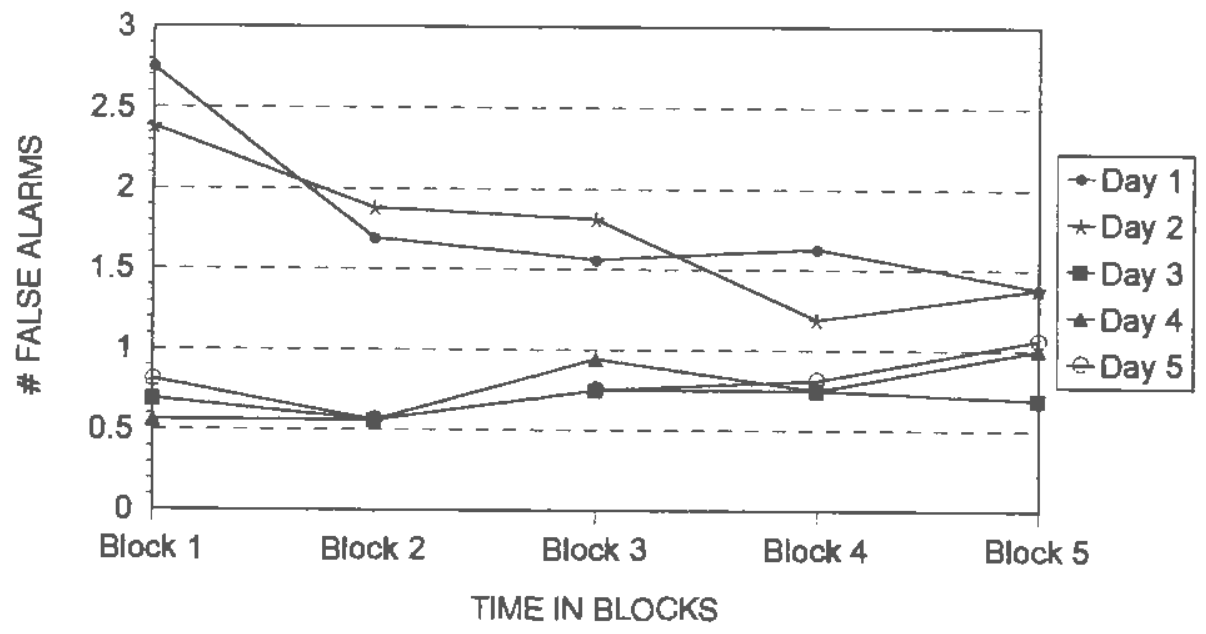

Figure 6. Practiced Task Mean Number of False Alarms Made by Day and Block 
CHANGES IN NUMBER OF FALSE ALARMS MADE

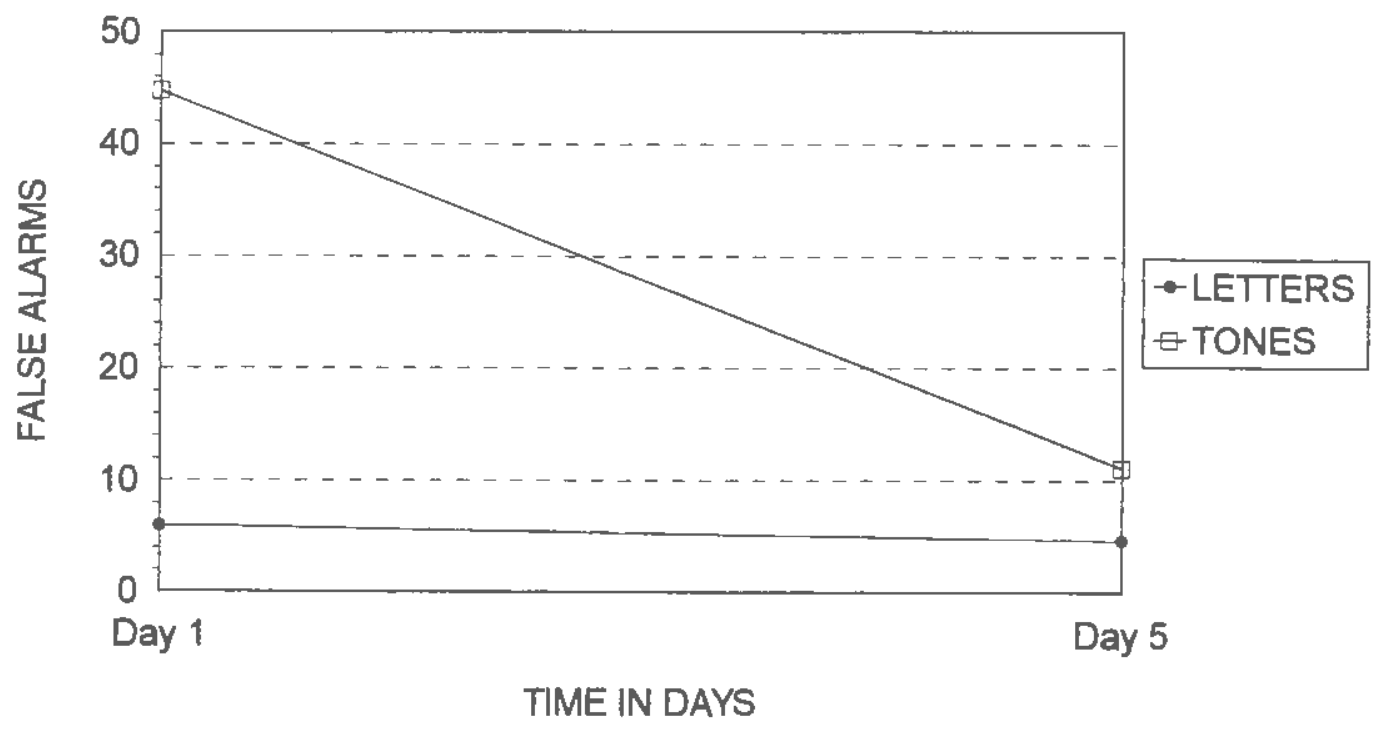

Figure 7. Unpracticed Task Number of False Alarms by Task 
UNPRACTICED TASK VIGILANCE DECREMENTS

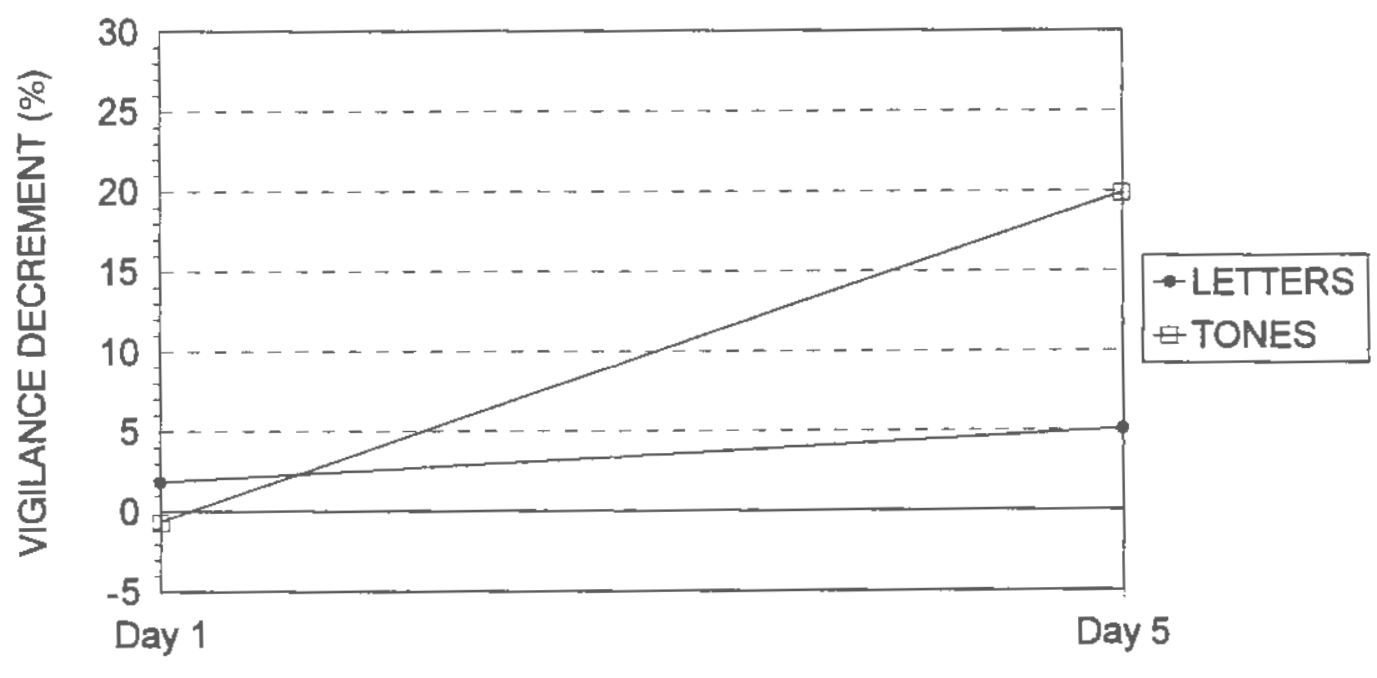

TIME IN DAYS

Figure 8. Unpracticed Task Vigilance Decrements by Task 
Group H

Informed Consent

Subjecu/Patient Name

Institution

Date of Birth

(Must be 18 or alder) Location

I have been asked to take part in a research project (described below). I should feel free to ask questions of the researcher. If I have more questions later, Dr. Valentino, the person mainly responsible for the study (792-4233), will discuss them with me. I may participate in the study, or I may change my mind and withdraw at any time. I understand that I will not receive payment for my participation, nor will I be penalized in any way if I withdraw.

Researchers at the Utiversity of Rhode Island Dept. of Psychology are conducting a study to observe the relationship between attention to verbal and non-verbal tasks. I understand that I will be asked to perform a simple mental task. This task known as a Continuous Performance Task, involves listening to letters, words or sounds and responding to some of them by pressing a button. I may be asked to fill out brief forms regarding personal information, such as my health, handedness, skills, etc.

This sudy will provide knowledge about how the brain processes information and where the processing may take place. This knowledge will help clinicians to do a better job recognizing abnormal attention patterns.

My privacy will be protected during the course of the study. Though the computer disk on which my records are stored may contain a label with my Social Security number, my data will always be labeled with a number code available only to Dr. Valentino. I will not be identified in any publication resulting fiom this study.

If I am not satisfied with the way the study is performed, I may discuss my complaints with Dr. Valentino or with the Psychology Department Chairperson, Dr. Janet Kulberg (792-2193), anonymously, if I choose. In addition, I may contact the office of the Vice Provost for Research, 70 Lower College Road, University of Rhode Island, Kingston, RI., telephone: (401) 792-2635.

I have read the Consent Form. My questions have been answered. My signature on this form means that I understand the information and I agree to participate in this study.

Signature

Print Name

Investigator

Print Name
Date

Date

\section{Appendix A}


IDH

1. Have you ever had a head injury?

a. yes

b. no

If answer to H 1 was yes, answer questions 2-6, if no skip to question 7

2. Were you seen in a hospital for your head injury?

a. yes

b. no

3. Approximate date(s) of head injury(s)?

4. Did you lose consciousness as a result of the head injury?

a. yes

b. no

Approximately how long in minutes?

5. Did you have annesia (can't remember what happened) for a period of time preceding the head injury?

a. yes

b. no

6. Did you have amnesia (can't remember what happened) for a period of time following the head injury?
a. yes
b. no

Approximately how long in minutes?

7. Have you ever lost consciousness anytime other than as a result of a head injury?

a. yes

b. no

Please describe

8. Have you ever or anyone in your immediate family ever had a neurological disorder such as epilepsy, Tourette's syndrome, or Parkinson's disease?

a. yes

b. no

Please describe

\section{Appendix B}


If answer to \#8 was yes, answer question 9, if no skip to question 10.

9. How far removed from yourself was the relative with a neurological condition?
a. myself
b. sibling
c. parent
d. grandparent
e. auntuncle

10. When was your most recent use of caffeine?
a. less than 4 bours ago
b. $4 \div$ to 12 his
c. $12 \div$ to $24 \mathrm{hrs}$
d. more than 1 day
e. never

11. When was your most recent use of tobacco?
a. less than 4 hours ago
b. 4 th to 12 hrs
c. $12+$ to 24 hrs
d. more than 1 day
e. never

12. Have you or anyone in your immediate family ever been diagnosed as having attention deficit disorder, dyslexia, or a leaming disability?
a. yes
b. no

Please describe

If answer to \#/2 was yes. answer question 13, if no slap to question 14.

13. How far removed from yourself was the relative with attentional disorder, dyslexia, or a leaming disability?
a. myself
b. sibling
c. parent
d. grandparent
e. aunduncle

14. Are you cureatly taking any medications?
a. yes
b. no

If yes, what medication

Dosage per day

What do you take this medication for? 
15. Have you ever been treated or hospitalized for psychiatric reasons such as depression, schizophrenia, bipolar disorder or arxiety?
a. yes
b. no

16. Has anyone in your immediate family ever been treated or hospitalized for psychiairic reasons such as depression, schizophrema, bipolar disorder or anxiety?

a. yes

b. no

17. Have you ever been treated for drug or alcohol problems?

a. yes

b. no

18. Are you aware of any complications associated with your birth?

a. yes

b. no

Please describe

19. Did you have any prolonged periods of high fever as an infant?
a. yes

b. no

20. Have you ever had a brain scan?

a. yes

b. no

When?

Why was it ordered?

21. Do you feel that you have normal hearing?
a. yes
b. no

If no, please explain 
1. Do you feel you are a normal drinker?

a. yes

b. no

If no, compared to others your age, do you feel that you drink:

a lessoften (or not at all)

b. more often

2. Do friends or relatives think you are nomal drinker?

a. yes

b. no

3. Have you ever attended a meeting of Alcoholics Anonymous (AA)?

a. yes

b. no

4. Have you ever lost friends or girlfriends/boyfriends due to your drinking?

5. Have you ever gotten into trouble at school or work because of your drinking?

6. Have you ever neglected your obligations, your family, or schoolwork for two or more days in a row because of your drinking?

a. yes

b. no

7. Have you ever had delirium tremors (DTs), severe shaking, heard voices or seen things that weren't there after heavy drinking?

a. yes

b. no

8. Have you ever gone to anyone for help about your drinking?

a. yes

b. no

9. Have you ever been in a hospital because of drinking?

b. no

10. Have you ever been arrested for drunk driving?

a. yes

b. no 
Group \#

Handedness Survey

adapted from the Edinburgh Inventory

Date

Have you ever had any tendency toward left-handedness?

YES NO

Is anyone in your family left-handed (eg. parents, siblings, etc.)?

YES

NO

If you are left-handed, do you write with an inverted hand posture?

YES

NO

Please indicate your preference in the use of hands in the following activities by putting + in the appropriate column. Where the preference is so strong that you would never try to use the other hand undess absolutely forced to, put \#. If in any case you are really indifferent, put + in both columns

Please try to answer all the questions, and only leave a blank if you have no experience at all of the object or task.

Right Left.

Writing

Drawing

Throwing

Scissors

Comb

Toothbrush

Spoon

Hammer

Striking a match

Opening a book (lid)

Dealing cards

Which foot do you prefer to kick with?

Which eye would you use to look through a telescope? 
ID \#

Brief Daily Questionaire

1. When was your most recent use of caffeine?

a. less than 4 hours ago

b. $4+$ to 12 hours

c. $12+$ to 24 hours

d. never

2. When was your most recent use of tobbaco?
a. less than 4 hours ago
b. $4+$ to 12 hours
c. $12+$ to 24 hours
d. never

3. When was your most recent use of alcohol?
a. less than 4 hours ago
b. $4+$ to 12 hours
c. $12+$ to 24 hours
d. never

4. Approximately how many hours of sleep did you have last night?
a. less than 5 hours
b. 5 to 6 hours
c. 7 to 9 hours
d. more than 9 hours

5. Have you been under any unusual stress in the last 24 hours?

a. yes

b. no

If yes, please explain

6. Are you currently taking any medication?
a. yes
b. no

If yes, please state: Type

\section{Dosage}

Reason

7. Have you developed symptoms of jllness (eg. cold, flu, etc.) in the last 24 hours?
a. yes
b. no

\section{Appendix C}




\section{BIBLIOGRAPHY}

Binford, J., \& Loeb, M. (1966). Changes within and over repeated sessions in criterion and effective sensitivity in an auditory vigilance task. Journal of Experimental Psychology, 72, 339-345.

Davies, D.R., \& Parasuraman, R. (1982). The psychology of vigilance. New York: Academic Press.

Fisk, A., \& Scerbo, M. (1987). Automatic and control processing approach to interpreting vigilance performance: A review and reevaluation, Human Factors, $29(6), 653-660$.

Halperin, J.M. (1996). Conceptualizing, describing, and measuring components of atterntion: A summary. In G.R. Lyon \& N.A. Krasnegor (Eds). Attention, memory, and executive function (pp. 119-136). Baltimore: Paul H. Brookes Publishing.

Halperin, J.M., Sharma, V., Greenblatt, E., \& Schwartz, S. (1991). Assessment of the continuous performance test: Reliability and validity in a nonreferred sample. Psychological Assessment: A Journal of Consulting and Clinical Psychology, 3(4), 603-608.

Keppel, G. (1991). Design and analysis: A researcher's handbook. New Jersey: Prentice Hall.

Koelega, H. (1996). Sustained attention. In O. Neumann and A. F. Sanders (Eds.), Handbook of perception and action, volume 3: Attention (pp. 277-331). New York: Academic Press. 
Koelega, H., Brinkman, J., Hendricks, L., \& Verbaten, M. (1989). Processing demands, effort, and individual differences in four different vigilance tasks. Human Factors, $3 I(1), 45-62$.

Leek, M., \& Watson, C. (1988). Auditory perceptual learning of tonal patterns. Perception and Psychophysics, 43(4), 389-394.

Loeb, M. \& Alluisi, E.A. (1984). Theories of attention. In D.H. Holding (Series Ed.) \& J.S. Warm (Vol. Ed.), Wiley series on studies in human performance: vol 4. Sustained attention in human performance (pp. 179-205). New York: John Wiley \& Sons, Ltd.

Neisser, U., \& Hirst, W. (1974). Effect of practice on the identification of auditory sequences. Perception \& Psychophysics, 15(2), 391-398.

Nickerson, R.S., \& Freeman, B. (1974). Discrimination of the order of the components of repeating tone sequences: Effects of frequency separation and extensive practice. Perception \& Psychophysics, 16(3), 471-477.

Parasuraman, R. (1984). The psychobiology of sustained attention. In D.H. Holding (Series Ed.) \& J.S. Warm (Vol. Ed.), Wiley series on studies in human performance: vol 4. Sustained attention in human performance (pp.61-101). New York: John Wiley \& Sons, Ltd.

Parasuraman, R., \& Davies, D. (1977). A taxonomic analysis of vigilance performance. In R.R. Mackie (Ed.), Vigilance: theory, operational performance, and physiological correlates (pp. 559-574). New York: Plenum.

Posner, M.I. \& Dehaene, S. (1994). Attentional networks. TINS, 17(2), 75-79. 
Posner, M.I. \& Petersen, S.E. (1990). The attention system of the human brain. Annual Review of Neuroscience, 13, 25-42.

Reeve, N.J. (1997). A comparison of continuous performance tasks using cognitive versus sensory stimuli. Unpublished master's thesis, University of Rhode Island.

Schneider, W., and Fisk, A. D. (1982). Degree of consistent training: Improvements in search performance and automatic process development. Perception and Psychophysics, 31, 160-168.

See, J., Howe, S., Warm, J., \& Dember, W. (1995). Meta-analysis of the sensitivity decrement in vigilance. Psychological Bulletin, 117, 230-249.

Stern, R.A., Arruda, J.E., Hooper, C.R., Wolfner, G.D. \& Morey, C.E. (in press). Visual analog mood scales to measure internal mood state in neurologically impaired patients: Description and initial validity evidence. Aphasiology.

Swets, J.A. \& Kristofferson, A.B. (1970). Attention. Annual Review of Psychology, 21, 339-366.

Tipper, S P., Eissenberg, T., \& Weaver, B. (1992). The effects of practice on mechanisms of attention. Bulletin of the Psychonomic Society, 30(1), 77-80.

Warm, J. S. (1984). An introduction to vigilance. In D.H. Holding (Series Ed.) \& J.S. Warm (Vol. Ed.), Wiley series on studies in human performance: vol 4. Sustained attention in human performance (pp. 1-14). New York: John Wiley \& Sons, Ltd. Williams, P. (1986). Processing demands, training, and the vigilance decrement. Human Factors, 28(5), 567-579. 